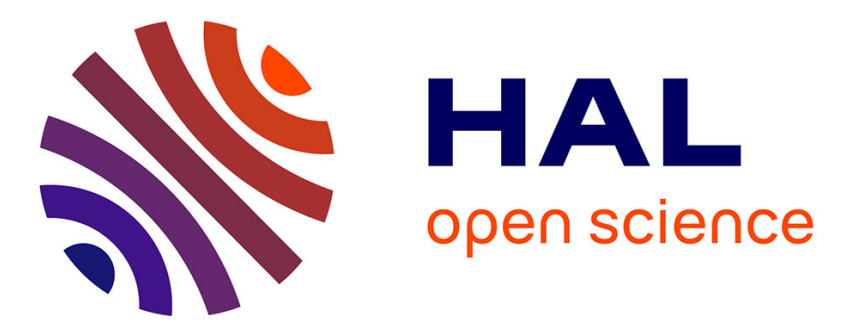

\title{
Prognostic value of the early change in neutrophil-to-lymphocyte ratio in metastatic pancreatic adenocarcinoma
}

Paul Mclellan, Julie Henriques, Feryel Ksontini, Solène Doat, Pascal Hammel, Jérome Desrame, Isabelle Trouilloud, Christophe Louvet, Daniel Pietrasz, Dewi Vernerey, et al.

\section{To cite this version:}

Paul Mclellan, Julie Henriques, Feryel Ksontini, Solène Doat, Pascal Hammel, et al.. Prognostic value of the early change in neutrophil-to-lymphocyte ratio in metastatic pancreatic adenocarcinoma. Clinics and Research in Hepatology and Gastroenterology, 2021, 45 (3), pp.101541. 10.1016/j.clinre.2020.08.016 . hal-03477687

\section{HAL Id: hal-03477687 https://hal.sorbonne-universite.fr/hal-03477687}

Submitted on 13 Dec 2021

HAL is a multi-disciplinary open access archive for the deposit and dissemination of scientific research documents, whether they are published or not. The documents may come from teaching and research institutions in France or abroad, or from public or private research centers.
L'archive ouverte pluridisciplinaire HAL, est destinée au dépôt et à la diffusion de documents scientifiques de niveau recherche, publiés ou non, émanant des établissements d'enseignement et de recherche français ou étrangers, des laboratoires publics ou privés. 
1 Prognostic value of early change in neutrophil to lymphocyte ratio in metastatic pancreatic

2 adenocarcinoma

4 Running title: Neutrophil-lymphocyte ratio in pancreatic cancer

7 Paul McLellan ${ }^{1,2} \mathrm{MD}$, Julie Henriques ${ }^{3,4} \mathrm{PhD}$, Feryel Ksontini ${ }^{5} \mathrm{MD}$, Solène Doat ${ }^{2} \mathrm{MD}$, Pascal 8 Hammel $^{6} \mathrm{PhD}$, Jérome Desrame ${ }^{7} \mathrm{PhD}$, Isabelle Trouilloud ${ }^{8} \mathrm{MD}$, Christophe Louvet ${ }^{9} \mathrm{MD}$, 9 Daniel Pietrasz ${ }^{10} \mathrm{MD}$, Dewi Vernerey ${ }^{3,4} \mathrm{PhD}$, Jean-Baptiste Bachet ${ }^{1,2} \mathrm{PhD}$

1. Sorbonne Université, 4 place Jussieu, 75005, Paris, France

2. Department of Hepato-Gastroenterology, Pitié-Salpêtrière, 47 boulevard de l'Hôpital 75013, APHP, Paris, France

3. Department of Methodology and Quality of Life Oncology, University Hospital, 3 Boulevard Alexandre Fleming, 25000, Besancon, France

4. Bourgogne Franche-Comté Université, INSERM, EFS BFC, UMR1098, Interactions Hôte-Greffon-Tumeur/Ingénierie Cellulaire et Génique, 8 rue du Docteur JeanFrançois-Xavier Girod 25020 Besançon, France

5. Department of Oncology, Institute Salah-Azaïz, Boulevard du 9 avril 1938, 1006 Tunis, Tunisia

6. Department of Digestive Oncology, Hôpital Beaujon, 100 boulevard du general Leclerc 92110 Clichy, France

7. Department of Gastroenterology, Hôpital Privé Jean Mermoz, 55 avenue Jean Mermoz 69008, Lyon, France

8. Department of Oncology, Hôpital Saint Antoine, 186 rue du faubourg Saint Antoine, 75012, Paris, France

9. Department of Oncology, Institut Mutualiste Montsouris, 54 avenue Jourdan, 75014 Paris, France 
10. Department of Hepato-Pancreato-Biliary Surgery, CHB, Hôpital Paul Brousse, 12 avenue Paul Vaillant Couturier, 94800 Villejuif, France

\section{Correspondence to}

Dr. Jean-Baptiste Bachet, Department of Gastroenterology and Digestive Oncology, Pitié-

Salpêtrière Hospital, Sorbonne University, 47-83 Boulevard de l'Hôpital, Paris 75013, France; Phone: 331-4216-1041; Fax: 331-4216-1238; E-mail: jean-baptiste.bachet@aphp.fr

\section{Funding}

None. The AFUGEM trial was supported by Celgene through grants to GERCOR, but had no role in study design, data collection, data analysis, data interpretation, or writing of the report.

\section{Conflict of interest}

JBB is a consultant/advisory board member for Amgen, Celgene, and Merck Serono, has received personal fees from Amgen, Bayer, Celgene, Merck Serono, Roche, Sanofi, Servier and non-financial support from Amgen, Merck Serono, and Roche. PH has received grants from Celgene and Roche; personal fees from Baxalta, Celgene, Ipsen, Lilly, Merck Serono, Novartis, and Pfizer and non-financial support from Celgene, Ipsen, Merck Serono, Novartis, and Pfizer. All other authors declare no conflict of interest.

\section{Ethics approval and consent to participate}

All experiments utilizing human samples were approved by the Ethical Committee of approved by the French ethics committee "Ile de France VI". All patients provided written informed consent before study enrolment.

This study was performed in accordance with the Declaration of Helsinki. 


\section{Abstract}

59 High neutrophil-lymphocyte (NLR) at diagnosis is a marker of poor prognosis in metastatic

60 pancreatic adenocarcinoma. Prognosis role of baseline NLR and its early change and NLR

61 evolution under first-line chemotherapy was determined. We conducted a retrospective study

62 based on one prospective cohort from a single center and a randomized open-label

63 multicenter randomized trial. Two hundred and twelve patients were analyzed. Baseline NLR

$64>5$ was an independent poor prognosis biomarker for overall survival $(\mathrm{HR}=2.01,95 \% \mathrm{CI}$ 1.33-3.05; $P=0.001)$ and for progression-free survival $(\mathrm{HR}=1.80,95 \% \mathrm{CI} 1.23-2.65$; $P=0.0026)$. According to NLR dynamics $(n=172)$, patients with NLR $\leq 5$ on days 1 and 15

67 had a significantly better prognosis than those with NLR $\leq 5$ on day 1 and $>5$ on day 15 $(\mathrm{HR}=2.23,95 \% \mathrm{CI} 1.18-4.21 ; P=0.013), \mathrm{NLR}>5$ on day 1 and $\leq 5$ on day $15(\mathrm{HR}=3.25$, 95\%CI 1.86-5.68; $P<0.001)$, and NLR $>5$ on days 1 and $15(\mathrm{HR}=3.37,95 \% \mathrm{CI} 1.93-5.90$; $P<0.001$ ). Over time, "bad responder" (progression-free survival <6 months) had a significantly higher mean NLR than "good responder" (group effect $P<0.0001$ ). Seven in 8 patients with baseline NLR $>5$ had circulating tumor DNA. We confirm the independent prognostic value of baseline NLR >5 in metastatic pancreatic cancer. NLR evolution is also a prognosis indicator in patients with NLR $\leq 5$.

Keywords: neutrophil to lymphocyte ratio, prognostic, metastatic pancreatic cancer, biomarker 
80 Highlights

$81 \quad$ - What is already known on this subject?

82 Neutrophils to lymphocytes ratio (NLR) is known as an independent prognosis marker at

83 diagnosis in metastatic pancreatic cancer. Few data are available about NLR follow up and

84 prognosis under chemotherapy.

$85 \quad$ - What are the new findings?

86 Early change in NLR can indicate very low survival.

87 Overtime, patients with good prognosis have lower NLR.

88 Association between NLR et circulating tumor DNA may be an interesting prognostic

89 biomarker.

90 - How might it impact on clinical practice in the foreseeable future?

91 We would advise practitioners to use high NLR during follow-up and chemotherapy

92 administration as an indicator of severity in order to help therapeutic decisions. 


\section{Background}

95 Pancreatic adenocarcinoma (PAC) is a severe disease and median overall survival (OS) in patients with metastatic disease is under 12 months.(1,2) The 1-year OS rate is about $30 \%$ and decreases at $7 \%$ after 5 years. Latest outcome figures confirm increase in the incident rate and prevalence of PAC in western countries.(3) PAC is the fourth cause of cancer deaths in the United States regardless of gender.(4)

100 First-line treatment of patients with metastatic PAC is based on chemotherapy such as FOLFIRINOX (oxaliplatin, irinotecan, 5-fluorouracil, and leucovorin) (2) or on the combination of gemcitabine and nab-paclitaxel in those with good Eastern Cooperative Oncology Group Performance Status (ECOG PS).(5,6) In PAC frail patients (ECOG PS >2), unfit to support polychemotherapy, gemcitabine monotherapy or best supportive care are the standard.(7)

Tumour markers such as ECOG PS 2, age > 65 years old, liver metastasis,(8) increase in lactate dehydrogenase (LDH), carcinoembryonic antigen (CEA), and carbohydrate antigen 19-9 (CA 19-9) levels have been defined as poor prognostic factors.(9)

CA 19-9, is currently the only FDA-approved biomarker used in PAC, but it has several

110 limitations including lack of specificity. This protein can be elevated in many situations such

111 as cholestasis or others cancers, and can be normal in patients with Lewis negative genotype,

112 representing about $5 \%-10 \%$ of the white population even in the advanced setting. $(10,11)$

113 Systemic inflammation is known to promote cancer and metastasis development.(12,13) The

114 role of inflammation and immune response within the tumour and its microenvironment is

115 discussed.(14) The tumour stroma in PAC seems to play a key role in providing drug resistance to immune participation by antigenic tumoral presentation.

117 Neutrophils represent the majority of white blood cells and participate to anti-tumoral

118 immunity and metastatic spreading.(15) Several tumour biomarkers for PAC have been

119 evaluated such as neutrophil-lymphocyte ratio (NLR), platelet-lymphocyte ratio, fibrinogen,

120 albumin, and C-reactive protein (CRP).(16-19) 
121 A high NLR has been reported as a poor prognosis marker in PAC,(8) but also in various 122 solid cancers.(20-22) In resectable PAC, it is associated with a higher risk of recurrent 123 metastatic disease and short OS.(16) In patients with metastatic PAC, the results of meta124 analysis have demonstrated that high values of NLR at diagnosis, ranging from 2.5 to 5 , 125 predict poorer OS.(23) NLR was shown to be a more accurate prognosis marker than the 126 platelet-lymphocyte ratio in PAC resectable tumours.(16)

127 To our knowledge little is known about NLR changes under chemotherapy. Our objective 128 was to analyse a NLR evolution pattern in patients receiving first-line metastatic PAC 129 treatment and to assess the impact of the NLR dynamic evolution on prognosis in this setting. 


\section{Patients}

134 We performed a retrospective analysis of patients derived from two different prospective cohorts. The first single-centre cohort consisted of consecutive patients who received first-

136 line metastatic PAC treatment at Pitié-Salpêtrière Hospital (the GHPS cohort) from January 1372010 to August 2016. Inclusion criteria were cytological or histologically confirmed PAC, 138 metastatic disease, age $\geq 18$ years, and signed consent for use of clinical and biological 139 information. These patients have been included in a prospective translational study (approved 140 by ethics committee) assessing the prognostic value of circulating tumour DNA (ctDNA).(24)

141 The second cohort consisted of patients included in the French open-label, multicentre,

142 randomized phase II AFUGEM trial (clinicaltrials.gov NCT01964534) comparing 143 gemcitabine and nab-paclitaxel to LV5FU2 and nab-paclitaxel.(6) The study protocol was 144 approved by the French ethics committee "Ile de France VI". All patients provided written 145 informed consent before study enrolment. Studies protocol were conformed to the ethical 146 guidelines of the 1975 Declaration of Helsinki (6th revision, 2008) as reflected in a priori 147 approval by the institution's human research committee.

\section{Data collection}

150 For the GHPS cohort, all clinical, pathological and biological data were collected from 151 patient medical records. These included the following: age at diagnosis, ECOG PS at 152 diagnosis, tumour location, tumour differentiation grade, prior history of surgery, number of 153 metastatic sites and location, dosages at diagnosis of albumin, platelets, CEA, CA 19-9 154 within 15 days before chemotherapy initiation, chemotherapy data (type of regimen, date of 155 the first and last cycle, reasons for treatment interruption), the date of the last assessment and 156 the date of death. 
157 For the AFUGEM cohort, clinical, pathological, and biological data were prospectively

158 collected in the electronic case report form as previously described.(25)

159 In the both cohorts, white blood count including neutrophil and lymphocyte count in 160 units $/ \mathrm{mm}^{3}$ were collected every 15 days during the first 2 months of treatment (on days 1, 15, 16130,45 , and 60) and on days 120 and 180, or at progression if it occurred before day 180. The 162 laboratory tests were performed within 4 days before chemotherapy. Each patient went to the 163 same laboratory during the follow-up. NLR was calculated by dividing the absolute 164 neutrophils count by the absolute lymphocytes counts as previously described.(16)

165 Progression was defined radiologically according to the RECIST 1.1 criteria or clinically if 166 stopping treatment due to altered general status or death.

167 Progression free-survival (PFS) was measured from the first chemotherapy administration to 168 the date of progression or death from any cause, whichever occurred first. OS was defined as 169 the time between first chemotherapy administration and death (all causes). Patients alive were censored at the last follow-up.

\section{Statistical analysis}

173 Patients' characteristics at baseline were compared between the two cohorts and between 174 patients with and without NLR at baseline. Median with interquartile range (IQR) and frequencies with percentage were used to describe continuous and categorical variables, respectively that were compared by the Wilcoxon test and Chi-square tests. The final analysed study population consisted of patients who had NLR baseline data.

178 Patients were categorized into high NLR at baseline group and a low NLR at baseline group 179 using the restricted cubic spline method to define the optimal cut-off value of baseline NLR. 180 Survival curves and follow-up were estimated using the Kaplan-Meier and reverse Kaplan181 Meier methods, respectively, described with median and 95\% confidence interval (95\% CI) 182 and compared with log-rank test. Hazard ratios (HRs) with 95\% CIs were estimated with Cox 183 proportional hazard models. Association between baseline characteristics including NLR at 
184 baseline and survivals was assessed with the univariate Cox model. Variables with $P$-value $<$

1850.1 were investigated in a multivariate analysis with a stepwise selection. The proportional

186 hazards assumption was checked graphically by plotting a log-minus log plot of the survival

187 and the correlation between variables.

188 In order to assess the dynamic change of NLR under first-line chemotherapy, patients were 189 categorized into four groups according to NLR at baseline (day 1) and on day 15: group 1/

190 NLR under the cut-off value on days 1 and 15, group 2/ NLR under the cut-off value on day 1

191 and above the cut-off value on day 15, group 3/ NLR above the cut-off value on day 1 and 192 under the cut-off value on day 15, and group 4/ NLR above the cut-off value on days 1 and

193 15. Both OS and PFS were assessed in all four groups.

194 For long term NLR follow-up, two groups of patients were defined: a group of "good 195 responders" with PFS $>6$ months and a group of "bad responders" with PFS <6 months.

196 Median NLR presented with IQR was compared at each date using the Wilcoxon test.

197 Evolution of NLR over time and across groups was estimated with a repeated measures 198 mixed model. Interaction between groups and time was tested.

199 All analyses were replicated separately in both cohorts to assess robustness of the results.

200 The database of the AFUGEM trial and the prospective cohort were locked for analysis on 201 September 2016 and December 2016, respectively.

202 Next-generation sequencing was used for ctDNA analysis as previously described.(24) An 203 exploratory analysis of the correlation between the presence of ctDNA and NLR was 204 performed. The association between the presence of ctDNA and survivals in patients with 205 low NLR was assessed.

206 All analyses were performed using SAS version 9.3 software (SAS Institute, Cary NC) and R 207 version 3.4.3 software ( $\mathrm{R}$ Development Core Team, Vienna, Austria; https://www.r208 project.org).

209 All tests were two-sided and $P$ values below 0.05 were considered statistically significant 


\section{Population of interest}

214 A total of 259 patients with proven metastatic PAC were selected from the GHPS cohort $(n=145)$ and the AFUGEM trial (n=114; Figure 1). In the GHPS cohort, patients had significantly more ECOG PS scores of 2 or 3, had more tumours with head location, had

217 more often presented with a prior history of surgery, had more frequently administered 218 adjuvant chemotherapy, had fewer liver metastasis, and had the higher incidence of low CA 219 19-9 levels (Table A.1). OS and PFS were similar between the two cohorts (Figures A.1 and A.2). We then pooled together the data from two prospective cohorts into a single cohort study $(n=259)$.

Of the 259 analysed patients, $212(81 \%)$ had NLR at baseline; $127(88 \%)$ in the GHPS cohort and $85(75 \%)$ in the AFUGEM cohort. Characteristics and survival of patients whose NLR was missing were comparable to those whose NLR was available (Table A.2 and Figures A.3 and A.4). The prognostic value of NLR analysis was performed on data from 212 patients excluding those whose NLR was missing at baseline. In GHPS cohort, ten patients with ECOG PS 3 due to symptoms relative to the disease and without comorbidity began a palliative chemotherapy. These patients were younger than patients with ECOG PS 0-2 (66.8 vs 69.4 years).

\section{Determination of the NLR cut-off value}

232 We used restricted cubic spline method to define the relation between NLR and OS. There was an increased risk of death until NLR was equal to 5 and then stabilization was observed (Figure A.5). We assumed that a baseline NLR value of 5 was a potential cut-off value for metastatic PAC patients. Therefore, this threshold was chosen for subsequent analyses. Overall, $50(24 \%)$ patients had NLR >5 at baseline. 


\section{Prognostic value of NLR at baseline}

239 We compared patients with low NLR $\leq 5(n=162)$ to those with high NLR $>5(n=50)$ at 240 baseline. The two groups were comparable in terms of sex, tumour differentiation grade, and 241 number of metastatic sites. Patients in the high NLR group had statistically poorer ECOG PS, 242 presented less frequently a history of surgical resection, and had more often lower albumin 243 and increased CEA levels (Table 1). Patients with NLR >5 at baseline had significantly 244 shorter PFS (median PFS 2.1 months, 95\% CI 1.6-3.4 versus 7.2 months, 95\% CI 5.4-8.2; $P<0.0001$ ) and OS (median OS 3.3 months, 95\% CI 2.2-5.2 versus 13.8 months, 95\% CI 11.0-16.6; $P<0.0001$ ) than those with NLR $\leq 5$ (Table 1; Figures A.6 and A.7). Results were unchanged after exclusion of the 10 patients with ECOG PS 3 at baseline (Figures A.8 and A.9). Among patients with ECOG PS 3 at baseline, the 6 patients with a NLR $>5$ died before two months whereas 2 of the 4 patients with a NLR $\leq 5$ were alive at 6 months.

\section{Univariate and multivariate analysis for OS and PFS at baseline}

In univariate analysis, poor prognosis factors for OS were ECOG PS 2-3 $(P<0.0001)$, body and tail tumour location $(P=0.0022)$, age $\geq 65$ years $(P=0.02)$, more than three metastatic sites $(P=0.0066), \mathrm{CEA} \geq 8(P=0.0018), \mathrm{CA} 19-9 \geq 1000 \mathrm{UI} / \mathrm{ml}(P<0.001)$, and NLR $>5(P<0.0001)$.

Factors associated with better prognosis were previous history of primary tumour resection ( $P=0.0012)$, well-differentiated tumour $(P=0.001)$, and albumin level $\geq 40 \mathrm{~g} / \mathrm{L} \quad(P=0.0005$;

Table 2).

In multivariate analysis, NLR $>5$ at baseline was an independent poor prognosis biomarker for OS $(\mathrm{HR}=2.01,95 \%$ CI 1.33-3.05; $P=0.001$; Table 2$)$ and for PFS $(\mathrm{HR}=1.80,95 \% \mathrm{CI}$

\section{Prognostic value of early change of NLR}

263 NLR data at baseline (day 1) and on day 15 were available for 171 patients. Patients with 
with NLR >5 at one or two dates (Figure 2). Consistent results were found for PFS (Figure

266 A.10). Patients with the worst prognostic were those with NLR >5 at baseline and on day 15.

267 Results were unchanged after exclusion of the 10 patients with ECOG PS 3 at baseline

268 (Figures A.11 and A.12).

269

\section{$270 \quad$ NLR evolution over time}

271 NLR differences were analysed at each date in the group of "good responders" with PFS $>6$ months ( $n=82)$ and in the group of "bad responders" $(n=121)$. "Bad responders" had a significantly higher median NLR at all dates than "good responders", except that on day 45.

274 The evolution of NLR over time showed a significant group effect $(P<0.0001)$, no significant 275 time effect $(P=0.1031)$, and nor interaction between both groups $(P=0.1252$; Table 3 and 276 Figure 3).

277

\section{Analyses in each study cohort}

279 Analyses were replicated in both cohorts separately (Tables A.5 to A.8). Patients with NLR $280 \leq 5$ at baseline and on day 15 had longer survival than other patients in both cohorts (Figure 281 A.13 to A.17). Results were unchanged when analysed in the fluoropyrimidine plus nabpaclitaxel arm of the AFUGEM trial alone (data not shown).

\section{NLR correlation with ctDNA}

285 ctDNA data before first-line chemotherapy was available for 52 patients in the GHPS cohort.

286 The ctDNA was more often detected in patients with NLR $>5$ at baseline $(7 / 8,87 \%)$ than in 287 those with NLR $\leq 5(22 / 40,55 \%)$. In patients with NLR $\leq 5$, the presence of ctDNA was associated with shorter PFS and OS (Figure A.18 and A.19). 


\section{DISCUSSION}

290 In this study, we confirmed that high NLR $(>5)$ at baseline is an independent prognostic

291 biomarker of OS and PFS in patients treated in first-line for metastatic PAC. Moreover, NLR

292 dynamic during the first 15 days of treatment also appears to be a prognostic biomarker in

293 patients with NLR $\leq 5$. Depending on PFS, the mean NLR was higher at each date for

294 patients with poor prognosis. Therefore, NLR increasing over time appears to be a prognostic

295 biomarker.

296 High NLR is known to be associated with poor OS in various solid cancers such as lung,(20)

297 breast cancer,(21) or ovarian.(22) In 2014, a meta-analysis of 100 studies comprising more

298 than 40000 patients confirmed the prognosis role of high NLR in gastro-oesophageal

299 cancers, cholangiocarcinoma, hepatocellular cancer, colorectal cancer, renal cell carcinoma,

300 and non-small cell lung cancer.(26) In PAC, NLR is also useful in patients with advanced

301 PAC treated by chemoradiotherapy alone (27) or in those receiving chemoradiotherapy

302 before curative surgery.(28)

303 The optimal NLR cut-off value of 5 in our study is consistent with that of previous studies.(5)

304 Nevertheless, in PAC, several NLR thresholds have been reported. In a recent meta-analysis

305 the cut-off values for elevated NLR were not consistent and ranged from 2.5 to 4 , so it did not

306 provide the most optimal value to be used.(23)

307 In our study, low ECOG PS and albumin, and high CEA levels were correlated with high

308 NLR. These factors are known to be associated with poor prognosis in metastatic PAC.

309 Systemic inflammation, reflected by high NLR, could emphasizes patients' symptoms such

310 as anorexia and asthenia, and, consecutively, be responsible of a poorer PS. NLR was lower

311 in patients who had curative intent resection. These patients undergo regular follow-up visits

312 after surgery. The tumor burden and the systemic inflammation associated are thus probably

313 less important at relapse diagnosis than in patients with metastasis at diagnosis. The step-wise

314 multivariate analysis strategy confirmed the independent poor prognosis value of baseline

315 high NLR. Other systemic biomarkers such as CRP, albumin, platelet-lymphocyte ratio may 
316 also give indication about the immune response of the host. Among them, high NLR seems to

317 be the most accurate.(19)

318 NLR is affordable and easily accessible biological marker. Various cytokines like interferon

319 or interleukine-6, and angiogenic factors (e.g. platelets derived growth factors) are the factors

320 of interest in evaluating prognosis of patients with PAC, $(17,29)$ though none of these is

321 currently recommended in clinical practice. Other inflammatory markers such as the Glasgow

322 prognostic score based on albumin and CRP or the NARCA prognosis score based on

323 neutrophils-to-albumin ratio and CA 19-9 have been also proposed.(30) Based on the first

324 international consensus on mandatory baseline and prognostic characteristics in future trials

325 for the treatment of unresectable PAC reported by Ter Veer et al., CRP and NLR were

326 defined as the compulsory measurements.(31)

327 The prognostic potential of the systemic inflammation-based markers in PAC is still unclear.

328 PAC is known for high inflammation not only in the tumour's stroma and microenvironment,

329 but also on a systemic level. We may hypothesize that the severity of systemic response

330 reflects aggressiveness of the tumour microenvironment. An elevated NLR may originate

331 from raised neutrophil or decreased lymphocyte counts. PAC microenvironment was proven

332 to induce tumour-associated neutrophils, which promotes metastatic invasion.(32)

333 Neutrophils can induce angiogenesis and suppress anti-tumour activity as such allowing tumour growth. They also produce or release various chemokines (including VEGF), metalloprotease, and reactive oxygen species that play a key role in tumour vascular development and migration.(33-35) The activation of the KRAS pathway, frequent in PAC,(36) was shown to recruit and activate neutrophils.(37) Transforming growth factor-beta

338 in the tumour stroma was shown to induce specific neutrophils with pro-tumour 339 phenotype.(38)

340 Decreased lymphocyte counts resulting in raised NLR may explain weaker defences against

341 the tumour and the cancer ability to escape chemotherapy response. Decreased lymphocyte

342 counts has been reported to be associated with shorter survival in PAC.(39) 
343 High NLR at baseline has been reported as a strong independent prognostic biomarker, but its

344 evolution over time could be also of interest. Chen et al. assessed NLR evolution between

345 baseline and after 2 cycles of chemotherapy in 132 patients treated for advanced or metastatic

346 PAC.(40) The value of 2.78 was selected as the NLR cut-off. Patients with increased NLR at

3471 month had a poorer prognostic than others. We performed the same analysis in our 348 population, but did not find any difference (Table A.12). However, the four groups strategy 349 used in our work emphasizes the poor prognosis associated with a high NLR level whatever 350 the moment. Chen et al reported relatively similar data with their methodology, in particular by defining their four sub-groups based on delta. Others studies are necessary to define the best method to use in clinical practice (delta of NLR or threshold at 5). We hypothesized that patients with high NLR at baseline turning $<5$ on day 15 would have an intermediate prognosis, but we did not observe it.

355 The presence of ctDNA is a prognostic biomarker at baseline in PAC as in other solid tumours.(24) Our exploratory results suggest an association between high NLR and presence of ctDNA, though one patient with NLR $>5$ did not have detectable ctDNA. Moreover, the presence of ctDNA seemed to be a prognostic biomarker in patients with NLR $<5$ at baseline. These two biomarkers may provide different information. NLR can reflect more the state of the inflammation and immunodepression associated to the disease whereas the ctDNA can be more correlated with the "aggressiveness" of the tumour cells or the tumour burden. In order to better understanding these points more data are necessary.

The retrospective design, the use of different chemotherapy regimens in first-line (Tables A.9 to A.11), the lack of data regarding corticosteroids use and granulocyte colony-stimulating factor administration, and the relative low number of patients in each subgroup for NLR dynamic analyses, especially in NLR $>5$ group, are limitations to our study. To explore potential biases, the NLR analyses were done for patients with and without NLR information at baseline and for each cohort in order to detect the subgroup effect. These analyses showed that NLR at baseline and its evolution under treatment are comparable between each cohort. 
370 Therefore, the study patients are representative of the general population of patients with

371 metastatic PAC receiving first-line chemotherapy in France. Given the heterogeneity of

372 chemotherapy regimens, we did not analyse the relation between NLR and treatment toxicity.

373 ctDNA data were only available for a subgroup of patients and these results are of an

374 exploratory nature.

375 The aim of assessing affordable, easily accessible, and performant biomarkers remains a key

376 to treatment optimization, combined with clinical and imaging features. With these

377 objectives, NLR appears as a promising dynamic and prognostic biomarker.

378 In conclusion, high NLR before or during chemotherapy was indicative of a poor prognosis

379 in patients with metastatic PAC. These results suggest the potential interest of following NLR

380 at each chemotherapy cycle. Further validation in prospective studies is required. 
383 We thank Magdalena Benetkiewicz for reviewing and editing assistance.

\section{REFERENCES}

1. Ryan DP, Hong TS, Bardeesy N. Pancreatic adenocarcinoma. N Engl J Med. 2014 27;371(22):2140-1.

2. Conroy T, Desseigne F, Ychou M, Bouché O, Guimbaud R, Bécouarn Y, et al. FOLFIRINOX versus gemcitabine for metastatic pancreatic cancer. N Engl J Med. 2011 May 12;364(19):1817-25.

3. Bray F, Ferlay J, Soerjomataram I, Siegel RL, Torre LA, Jemal A. Global cancer statistics 2018: GLOBOCAN estimates of incidence and mortality worldwide for 36 cancers in 185 countries. CA Cancer J Clin. 2018 Nov;68(6):394-424.

4. Siegel RL, Miller KD, Jemal A. Cancer statistics, 2016: Cancer Statistics, 2016. CA Cancer J Clin. 2016 Jan;66(1):7-30.

5. Goldstein D, El-Maraghi RH, Hammel P, Heinemann V, Kunzmann V, Sastre J, et al. nab-Paclitaxel plus gemcitabine for metastatic pancreatic cancer: long-term survival from a phase III trial. J Natl Cancer Inst. 2015 Feb;107(2).

6. Bachet J-B, Chibaudel B, Bonnetain F, Validire P, Hammel P, André T, et al. A randomized phase II study of weekly nab-paclitaxel plus gemcitabine or simplified LV5FU2 as first-line therapy in patients with metastatic pancreatic cancer: the AFUGEM GERCOR trial. BMC Cancer. 2015 Oct 6;15:653.

7. Burris HA, Moore MJ, Andersen J, Green MR, Rothenberg ML, Modiano MR, et al. Improvements in survival and clinical benefit with gemcitabine as first-line therapy for patients with advanced pancreas cancer: a randomized trial. J Clin Oncol Off J Am Soc Clin Oncol. 1997 Jun;15(6):2403-13.

8. Tabernero J, Chiorean EG, Infante JR, Hingorani SR, Ganju V, Weekes C, et al. Prognostic factors of survival in a randomized phase III trial (MPACT) of weekly nabpaclitaxel plus gemcitabine versus gemcitabine alone in patients with metastatic pancreatic cancer. The Oncologist. 2015 Feb;20(2):143-50.

9. Tas F, Karabulut S, Ciftci R, Sen F, Sakar B, Disci R, et al. Serum levels of LDH, CEA, and CA19-9 have prognostic roles on survival in patients with metastatic pancreatic cancer receiving gemcitabine-based chemotherapy. Cancer Chemother Pharmacol. 2014 Jun;73(6):1163-71.

10. Galli C, Basso D, Plebani M. CA 19-9: handle with care. Clin Chem Lab Med. 2013 Jul;51(7):1369-83.

11. Hamada E, Taniguchi $\mathrm{T}$, Baba S, Maekawa M. Investigation of unexpected serum CA19-9 elevation in Lewis-negative cancer patients. Ann Clin Biochem. 2012 May;49(Pt 3):266-72. 
12. Wu Y, Zhou BP. Inflammation: a driving force speeds cancer metastasis. Cell Cycle Georget Tex. 2009 Oct 15;8(20):3267-73.

13. Grivennikov SI, Greten FR, Karin M. Immunity, inflammation, and cancer. Cell. 2010 Mar 19;140(6):883-99.

14. Feig C, Gopinathan A, Neesse A, Chan DS, Cook N, Tuveson DA. The pancreas cancer microenvironment. Clin Cancer Res Off J Am Assoc Cancer Res. 2012 Aug $15 ; 18(16): 4266-76$.

15. Casanova-Acebes M, Nicolás-Ávila JA, Li JL, García-Silva S, Balachander A, RubioPonce A, et al. Neutrophils instruct homeostatic and pathological states in naive tissues. J Exp Med. 2018 Nov 5;215(11):2778-95.

16. Bhatti I, Peacock O, Lloyd G, Larvin M, Hall RI. Preoperative hematologic markers as independent predictors of prognosis in resected pancreatic ductal adenocarcinoma: neutrophil-lymphocyte versus platelet-lymphocyte ratio. Am J Surg. 2010 Aug;200(2):197-203.

17. Mroczko B, Groblewska M, Gryko M, Kedra B, Szmitkowski M. Diagnostic usefulness of serum interleukin 6 (IL-6) and C-reactive protein (CRP) in the differentiation between pancreatic cancer and chronic pancreatitis. J Clin Lab Anal. 2010;24(4):25661 .

18. Wu M, Guo J, Guo L, Zuo Q. The C-reactive protein/albumin ratio predicts overall survival of patients with advanced pancreatic cancer. Tumour Biol J Int Soc Oncodevelopmental Biol Med. 2016 Sep;37(9):12525-33.

19. Oh D, Pyo J-S, Son BK. Prognostic Roles of Inflammatory Markers in Pancreatic Cancer: Comparison between the Neutrophil-to-Lymphocyte Ratio and Platelet-toLymphocyte Ratio. Gastroenterol Res Pract [Internet]. 2018 Jun 7 [cited 2018 Nov 14];2018. Available from: https://www.ncbi.nlm.nih.gov/pmc/articles/PMC6011084/

20. Zhao Q-T, Yang Y, Xu S, Zhang X-P, Wang H-E, Zhang H, et al. Prognostic role of neutrophil to lymphocyte ratio in lung cancers: a meta-analysis including 7,054 patients. OncoTargets Ther. 2015;8:2731-8.

21. Liu X, Qu J-K, Zhang J, Yan Y, Zhao X-X, Wang J-Z, et al. Prognostic role of pretreatment neutrophil to lymphocyte ratio in breast cancer patients: A meta-analysis. Medicine (Baltimore). 2017 Nov;96(45):e8101.

22. Chen S, Zhang L, Yan G, Cheng S, Fathy AH, Yan N, et al. Neutrophil-to-Lymphocyte Ratio Is a Potential Prognostic Biomarker in Patients with Ovarian Cancer: A MetaAnalysis. BioMed Res Int. 2017;2017:7943467.

23. Yang J-J, Hu Z-G, Shi W-X, Deng T, He S-Q, Yuan S-G. Prognostic significance of neutrophil to lymphocyte ratio in pancreatic cancer: A meta-analysis. World $\mathrm{J}$ Gastroenterol WJG. 2015 Mar 7;21(9):2807-15.

24. Pietrasz D, Pécuchet N, Garlan F, Didelot A, Dubreuil O, Doat S, et al. Plasma Circulating Tumor DNA in Pancreatic Cancer Patients Is a Prognostic Marker. Clin Cancer Res Off J Am Assoc Cancer Res. 2017 Jan 1;23(1):116-23.

25. Bachet J-B, Hammel P, Desramé J, Meurisse A, Chibaudel B, André T, et al. Nabpaclitaxel plus either gemcitabine or simplified leucovorin and fluorouracil as first-line 
therapy for metastatic pancreatic adenocarcinoma (AFUGEM GERCOR): a noncomparative, multicentre, open-label, randomised phase 2 trial. Lancet Gastroenterol Hepatol. 2017;2(5):337-46.

26. Templeton AJ, McNamara MG, Šeruga B, Vera-Badillo FE, Aneja P, Ocaña A, et al. Prognostic role of neutrophil-to-lymphocyte ratio in solid tumors: a systematic review and meta-analysis. J Natl Cancer Inst. 2014 Jun;106(6):dju124.

27. Lee BM, Chung SY, Chang JS, Lee KJ, Seong J. The Neutrophil-Lymphocyte Ratio and Platelet-Lymphocyte Ratio Are Prognostic Factors in Patients with Locally Advanced Pancreatic Cancer Treated with Chemoradiotherapy. Gut Liver. 2018 May $15 ; 12(3): 342-52$.

28. Hasegawa S, Eguchi H, Tomokuni A, Tomimaru Y, Asaoka T, Wada H, et al. Pretreatment neutrophil to lymphocyte ratio as a predictive marker for pathological response to preoperative chemoradiotherapy in pancreatic cancer. Oncol Lett. 2016 Feb;11(2):1560-6.

29. Yako YY, Brand M, Smith M, Kruger D. Inflammatory cytokines and angiogenic factors as potential biomarkers in South African pancreatic ductal adenocarcinoma patients: A preliminary report. Pancreatol Off J Int Assoc Pancreatol IAP Al. 2017 Jun;17(3):438-44.

30. Tingle SJ, Severs GR, Goodfellow M, Moir JA, White SA. NARCA: A novel prognostic scoring system using neutrophil-albumin ratio and Ca19-9 to predict overall survival in palliative pancreatic cancer. J Surg Oncol. 2018 Sep;118(4):680-6.

31. ter Veer E, van Rijssen LB, Besselink MG, Mali RMA, Berlin JD, Boeck S, et al. Consensus statement on mandatory measurements in pancreatic cancer trials (COMMPACT) for systemic treatment of unresectable disease. Lancet Oncol. 2018 Mar;19(3):e151-60.

32. Bekes EM, Schweighofer B, Kupriyanova TA, Zajac E, Ardi VC, Quigley JP, et al. Tumor-recruited neutrophils and neutrophil TIMP-free MMP-9 regulate coordinately the levels of tumor angiogenesis and efficiency of malignant cell intravasation. Am $\mathbf{J}$ Pathol. 2011 Sep;179(3):1455-70.

33. el-Hag A, Clark RA. Immunosuppression by activated human neutrophils. Dependence on the myeloperoxidase system. J Immunol Baltim Md 1950. 1987 Oct 1;139(7):240613.

34. Scapini P, Morini M, Tecchio C, Minghelli S, Di Carlo E, Tanghetti E, et al. CXCL1/macrophage inflammatory protein-2-induced angiogenesis in vivo is mediated by neutrophil-derived vascular endothelial growth factor-A. J Immunol Baltim Md 1950. 2004 Apr 15;172(8):5034-40.

35. Di Carlo E, Forni G, Musiani P. Neutrophils in the antitumoral immune response. Chem Immunol Allergy. 2003;83:182-203.

36. Bailey P, Chang DK, Nones K, Johns AL, Patch A-M, Gingras M-C, et al. Genomic analyses identify molecular subtypes of pancreatic cancer. Nature. 2016 Mar 3;531(7592):47-52. 
37. Zhang Y, Yan W, Collins MA, Bednar F, Rakshit S, Zetter BR, et al. Interleukin-6 is required for pancreatic cancer progression by promoting MAPK signaling activation and oxidative stress resistance. Cancer Res. 2013 Oct 15;73(20):6359-74.

38. Fridlender ZG, Sun J, Kim S, Kapoor V, Cheng G, Ling L, et al. Polarization of TumorAssociated Neutrophil Phenotype by TGF- $\beta$ : "N1" versus "N2" TAN. Cancer Cell. 2009 Sep 8;16(3):183-94.

39. Fogar P, Sperti C, Basso D, Sanzari MC, Greco E, Davoli C, et al. Decreased total lymphocyte counts in pancreatic cancer: an index of adverse outcome. Pancreas. 2006 Jan;32(1):22-8.

40. Chen Y, Yan H, Wang Y, Shi Y, Dai G. Significance of baseline and change in neutrophil-to-lymphocyte ratio in predicting prognosis: a retrospective analysis in advanced pancreatic ductal adenocarcinoma. Sci Rep. 2017 09;7(1):753. 


\section{Table and Figure Legends}

518 Table 1. Comparison of characteristics between patients according to NLR at baseline

519 Table 2. Univariate and multivariate analyses of the association between baseline patient

520 characteristics and overall survival

521 Table 3. Description of NLR over time according to progression-free survival under first-line

522 chemotherapy $(6<$ months or $>6$ months) (A) and mixed model of repeated measures and time

523 as categorical variable (from day 1 to day 180) (B)

524

525 Figure 1. Population flow chart

526 Figure 2. Overall survival curves according to NLR at baseline and on day 15

527 Figure 3. Evolution curves of NLR from day 1 to day 180 under first-line of chemotherapy in 528 "good responders" (PFS >6 months) and "bad responders" (PFS <6 months) $(n=212)$

529

530 Abbreviations

531 ECOG PS: Eastern Cooperative Oncology Group Performance Status

532 CA 19-9: carbohydrate antigen 19-9

533 CEA: carcinoembryonic antigen

534 NLR: neutrophil to lymphocyte ratio

535 OS: overall survival

536 PFS: progression-free survival

537 HR: hazard ratio

538 CI: confidence interval

539 IQR: interquartile range

540 GHPS: Pitié-Salpêtrière Hospital Group 


\begin{tabular}{|c|c|c|c|c|c|}
\hline Characteristics & & $\begin{array}{c}\text { NLR available } \\
N=\mathbf{2 1 2} \\
n(\%)\end{array}$ & $\begin{array}{c}\text { NLR } \leq 5 \\
N=162 \\
n(\%)\end{array}$ & $\begin{array}{c}\text { NLR > 5 } \\
N=\mathbf{5 0} \\
n(\%)\end{array}$ & $P$-value \\
\hline \multirow[t]{3}{*}{ Age* } & Median & 65.8 & 65.3 & 67.9 & 0.059 \\
\hline & IQR & $60.3-73.0$ & $58.9-72.7$ & $62.5-73.8$ & \\
\hline & Missing & 9 & 4 & 5 & \\
\hline \multirow[t]{2}{*}{ Gender** } & Male & $131(62)$ & $103(64)$ & $28(56)$ & 0.3349 \\
\hline & Female & $81(38)$ & $59(36)$ & $22(44)$ & \\
\hline \multirow[t]{4}{*}{ ECOG PS** } & 0 & $67(32)$ & $59(36)$ & $8(16)$ & 0.0002 \\
\hline & 1 & $83(39)$ & $67(41)$ & $16(32)$ & \\
\hline & 2 & $52(24)$ & $32(20)$ & $20(40)$ & \\
\hline & 3 & $10(5)$ & $4(2)$ & $6(12)$ & \\
\hline \multirow[t]{5}{*}{ Primary tumour location $* *$} & Head & $107(50)$ & $85(53)$ & $21(42)$ & 0.1762 \\
\hline & Body & $38(18)$ & $26(16)$ & $12(24)$ & \\
\hline & Tail & $44(21)$ & $30(18)$ & $14(28)$ & \\
\hline & Head and body & $15(7)$ & $14(9)$ & $1(2)$ & \\
\hline & Body and tail & $8(4)$ & $6(4)$ & $2(4)$ & \\
\hline \multirow[t]{3}{*}{ Stage at diagnosis $* *$} & $\mathrm{I} / \mathrm{II}$ & 40 (19) & $36(22)$ & $4(8)$ & 0.0796 \\
\hline & III & $7(3)$ & $5(3)$ & $2(4)$ & \\
\hline & IV & $165(78)$ & $121(75)$ & $44(88)$ & \\
\hline \multirow{4}{*}{$\begin{array}{l}\text { Tumour differentiation } \\
\text { grade }\end{array}$} & Well & $64(37)$ & $52(38)$ & $12(33)$ & 0.6109 \\
\hline & Moderate & $85(49)$ & $68(49)$ & $17(47)$ & \\
\hline & Poor & $25(14)$ & $18(13)$ & $7(19)$ & \\
\hline & Missing & 38 & 24 & 14 & \\
\hline \multirow[t]{3}{*}{ Number of metastatic sites } & 1 & $131(62)$ & $104(65)$ & $27(54)$ & 0.1611 \\
\hline & $\geq 2$ & $79(38)$ & $56(35)$ & $23(46)$ & \\
\hline & Missing & 2 & 2 & 0 & \\
\hline Liver metastases $* *$ & & $138(65)$ & $103(64)$ & $35(70)$ & 0.4051 \\
\hline Resection of primary tumour** & & $59(28)$ & $52(32)$ & $7(14)$ & 0.0126 \\
\hline \multirow[t]{3}{*}{ Adjuvant chemotherapy } & & & & & 0.062 \\
\hline & Yes & 40 (19) & $35(21)$ & $5(10)$ & \\
\hline & Missing & 2 & 2 & 0 & \\
\hline \multirow[t]{3}{*}{$\operatorname{Albumin}(\mathrm{g} / \mathrm{L})$} & Median & 37 & 38 & 34 & 0.0341 \\
\hline & IQR & $32-41$ & $34-41$ & $30-40$ & \\
\hline & Missing & 11 & 8 & 3 & \\
\hline \multirow[t]{3}{*}{ CA 19-9 (UI/ml) } & Median & 450 & 390 & 2143 & 0.09 \\
\hline & IQR & $37-3616$ & $39.90-1831.5$ & $31-10000$ & \\
\hline & Missing & 15 & 10 & 5 & \\
\hline \multirow[t]{3}{*}{ CEA (ng/ml) } & Median & 5 & 4 & 8.8 & 0.0308 \\
\hline & IQR & $2-19$ & $2-17$ & $3-32$ & \\
\hline & Missing & 17 & 11 & 6 & \\
\hline \multirow[t]{2}{*}{ Cohort* } & AFUGEM & $85(40)$ & $64(39)$ & $21(42)$ & 0.7531 \\
\hline & GHPS & $127(60)$ & $98(60)$ & $29(58)$ & \\
\hline Death & & $159(77)$ & $112(71)$ & $47(94)$ & 0.0009 \\
\hline Progression & & $120(57)$ & $98(60)$ & $22(44)$ & 0.0397 \\
\hline OS median $(95 \% \mathrm{CI})$ & & $10.7(8.9-13.3)$ & $13.8(11.0-16.6)$ & $3.3(2.2-5.2)$ & $<0.0001$ \\
\hline PFS median (95\% CI) & & $5.4(4.4-6.2)$ & $7.2(5.4-8.2)$ & $2.1(1.6-3.4)$ & $<0.0001$ \\
\hline
\end{tabular}

544 Table 1. Comparison of characteristics between patients according to NLR at baseline

546 Abbreviations: NLR=neutrophil to lymphocyte ratio; ECOG PS=Eastern Cooperative Oncology Group

547 Performance Status; CA 19-9=carbohydrate antigen 19-9; CEA=carcinoembryonic antigen; IQR=interquartile

548 range; $\mathrm{OS}=$ overall survival; $\mathrm{PFS}=$ progression-free survival

$549 *$ Age at randomization for AFUGEM and age at first-line chemotherapy initiation for retrospective study

$550 * *$ no missing data 
551 Table 2. Univariate and multivariate analyses of the association between baseline patient characteristics and overall survival

\begin{tabular}{|c|c|c|c|c|c|c|c|c|}
\hline & & \multicolumn{4}{|c|}{ Univariate analysis } & \multicolumn{3}{|c|}{$\begin{array}{c}\text { Multivariate analysis } \\
N=186 ; N \text { events }=133\end{array}$} \\
\hline & & $\overline{N \text { (events) }}$ & HR & $95 \% \mathrm{CI}$ & $P$-value & HR & $95 \% \mathrm{CI}$ & $P$-value \\
\hline \multirow{2}{*}{ Age } & $<65$ years & $90(63)$ & 1 & & 0.0208 & & & \\
\hline & $\geq 65$ years & $113(88)$ & 1.47 & $1.06-2.04$ & & & & \\
\hline \multirow{2}{*}{ Gender } & Male & $131(99)$ & 1 & & 0.1338 & & & \\
\hline & Female & $81(52)$ & 0.77 & $0.55-1.08$ & & & & \\
\hline \multirow{2}{*}{ ECOG PS } & $0-1$ & $150(103)$ & 1 & & $<0.0001$ & 1 & & 0.0002 \\
\hline & $2-3$ & $62(48)$ & 2.85 & $2-4.05$ & & 2.32 & $1.48-3.62$ & \\
\hline \multirow{2}{*}{ Primary tumour location } & Head/ head and body & $122(82)$ & 1 & & 0.0022 & 1 & & 0.0086 \\
\hline & Other & $90(69)$ & 1.66 & $1.20-2.30$ & & 1.66 & $1.14-2.43$ & \\
\hline \multirow{2}{*}{ Differentiation grade } & Poor and moderate & $110(86)$ & 1 & & 0.001 & & & \\
\hline & Well & $64(39)$ & 0.46 & $0.31-0.69$ & & & & \\
\hline \multirow{3}{*}{ Resection of primary tumour } & No & $153(111)$ & 1 & & 0.0012 & 1 & & 0.0133 \\
\hline & Yes & $59(40)$ & 0.54 & $0.37-0.78$ & & 0.57 & $0.37-0.89$ & \\
\hline & 1 & $131(93)$ & 1 & & 0.0066 & 1 & & 0.0353 \\
\hline \multirow[t]{2}{*}{ Number of metastatic sites } & 2 & $58(41)$ & 1.02 & $0.71-1.48$ & & 1.23 & $0.82-1.84$ & \\
\hline & $\geq 3$ & $21(16)$ & 2.37 & $1.38-4.06$ & & 2.19 & $1.20-4.01$ & \\
\hline \multirow{2}{*}{ Albumin (g/l) } & $<40$ & $132(101)$ & 1 & & 0.0005 & 1 & & 0.0006 \\
\hline & $\geq 40$ & $69(43)$ & 0.53 & $0.37-0.76$ & & 0.48 & $0.31-0.73$ & \\
\hline \multirow{2}{*}{ CA 19-9 (UI/ml) } & $<1000$ & $120(79)$ & 1 & & $<0.0001$ & 1 & & 0.0206 \\
\hline & $\geq 1000$ & $77(62)$ & 2.16 & $1.53-3.06$ & & 1.57 & $1.07-2.30$ & \\
\hline \multirow{2}{*}{ CEA (ng/ml) } & $<8$ & $115(84)$ & 1 & & 0.0118 & & & \\
\hline & $\geq 8$ & $80(57)$ & 1.55 & $1.10-2.17$ & & & & \\
\hline \multirow{2}{*}{ NLR at baseline } & $\leq 5$ & $162(109)$ & 1 & & $<0.0001$ & 1 & & 0.001 \\
\hline & $>5$ & $50(42)$ & 3.22 & $2.23-4.64$ & & 2.01 & $1.33-3.05$ & \\
\hline
\end{tabular}

553 Abbreviations: HR=hazard ratio; NLR=neutrophil to lymphocyte ratio; ECOG PS=Eastern Cooperative Oncology Group Performance Status; CA 19-9=carbohydrate antigen 19-9;

$554 \mathrm{CEA}=$ carcinoembryonic antigen; $\mathrm{IQR}=$ interquartile range 
Table 3. Description of NLR over time according to progression-free survival under first-line chemotherapy ( $<6$ months or $>6$ months) and results of mixed model of repeated measures and time as categorical variable (from day 1 to day 180)

\section{Description of NLR over time according to progression-free survival}

Under first-line chemotherapy ( $<6$ months or $>6$ months)

\begin{tabular}{|c|c|c|c|c|c|c|}
\hline & Responder & $N$ & Mean & SD & Median & IQR \\
\hline \multirow[t]{2}{*}{ D1 } & bad & 129 & 4.67 & 4.04 & 3.80 & $2.0-6.20$ \\
\hline & good & 83 & 3.00 & 2.02 & 2.69 & $1.75-3.49$ \\
\hline \multirow[t]{2}{*}{ D15 } & bad & 98 & 4.08 & 5.76 & 2.63 & $1.28-4.81$ \\
\hline & good & 74 & 2.36 & 1.82 & 1.82 & $1.22-2.88$ \\
\hline \multirow[t]{2}{*}{ D30 } & bad & 83 & 3.77 & 3.48 & 2.69 & $1.47-5.13$ \\
\hline & good & 75 & 2.45 & 1.81 & 1.89 & $1.45-3.17$ \\
\hline \multirow[t]{2}{*}{ D45 } & bad & 85 & 4.39 & 4.72 & 2.76 & $1.53-5.31$ \\
\hline & good & 79 & 3.02 & 2.74 & 2.29 & $1.31-3.32$ \\
\hline \multirow[t]{2}{*}{ D60 } & bad & 58 & 4.09 & 4.18 & 2.83 & $1.79-4.25$ \\
\hline & good & 74 & 3.16 & 3.42 & 2.11 & $1.18-3.28$ \\
\hline \multirow[t]{2}{*}{ D120 } & bad & 31 & 5.37 & 4.35 & 3.30 & $2.45-7.25$ \\
\hline & good & 66 & 2.45 & 1.92 & 2.05 & $1.28-2.95$ \\
\hline \multirow[t]{2}{*}{ D180 } & bad & 15 & 4.81 & 2.47 & 5.53 & $2.53-6.23$ \\
\hline & good & 59 & 2.83 & 2.40 & 1.98 & $1.32-3.29$ \\
\hline \multicolumn{7}{|c|}{ Results of mixed model of repeated measures and time as categorical variable (from day 1 to day 180) } \\
\hline Effect & $N$ DF & Den DF & Value & $>\mathbf{F}$ & & \\
\hline Good responder & 1 & 210 & 34.69 & $<0.0001$ & & \\
\hline Evaluation & 6 & 785 & 1.77 & 0.1031 & & \\
\hline Responder*evaluation & 6 & 785 & 1.67 & 0.1252 & & \\
\hline
\end{tabular}




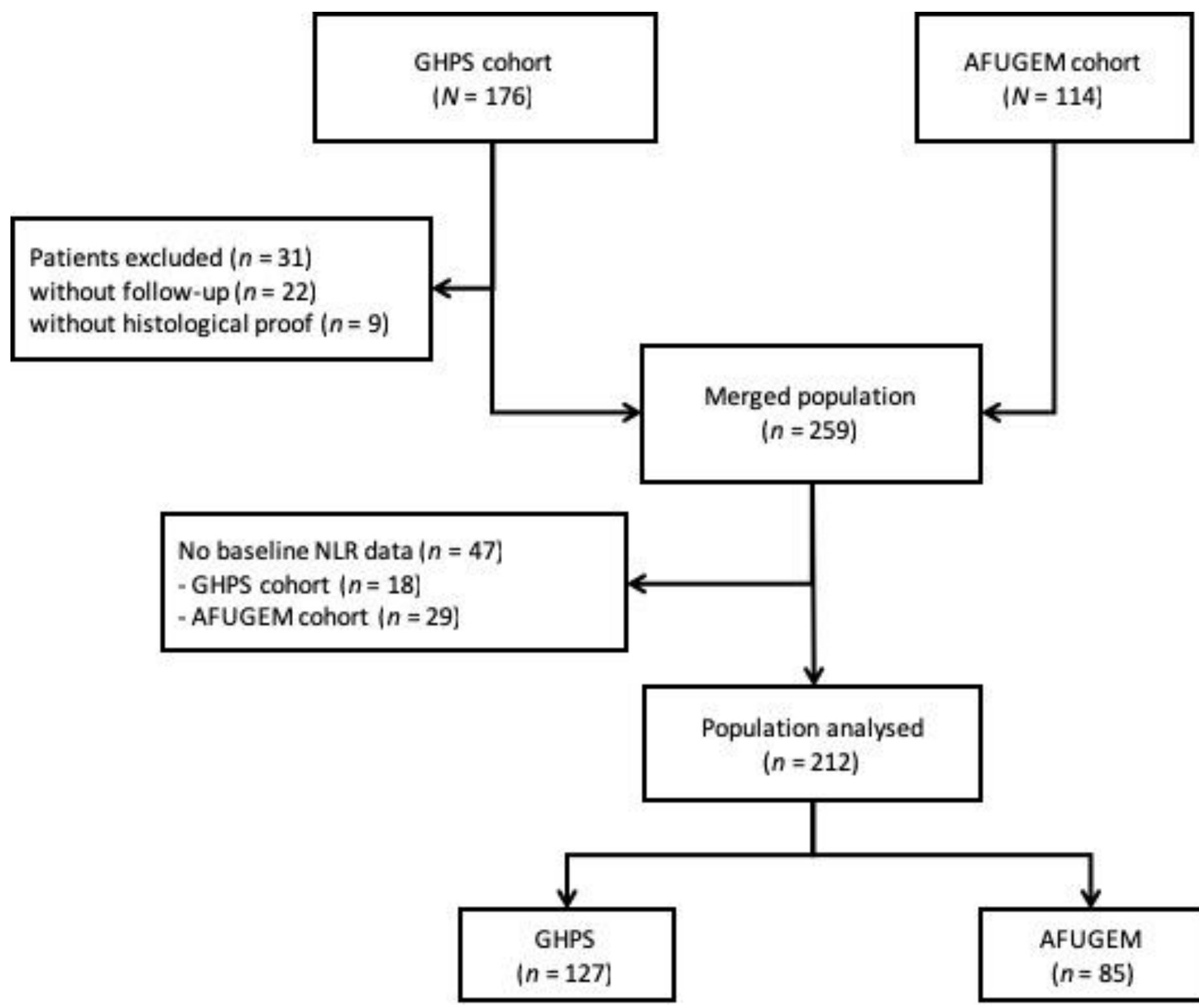




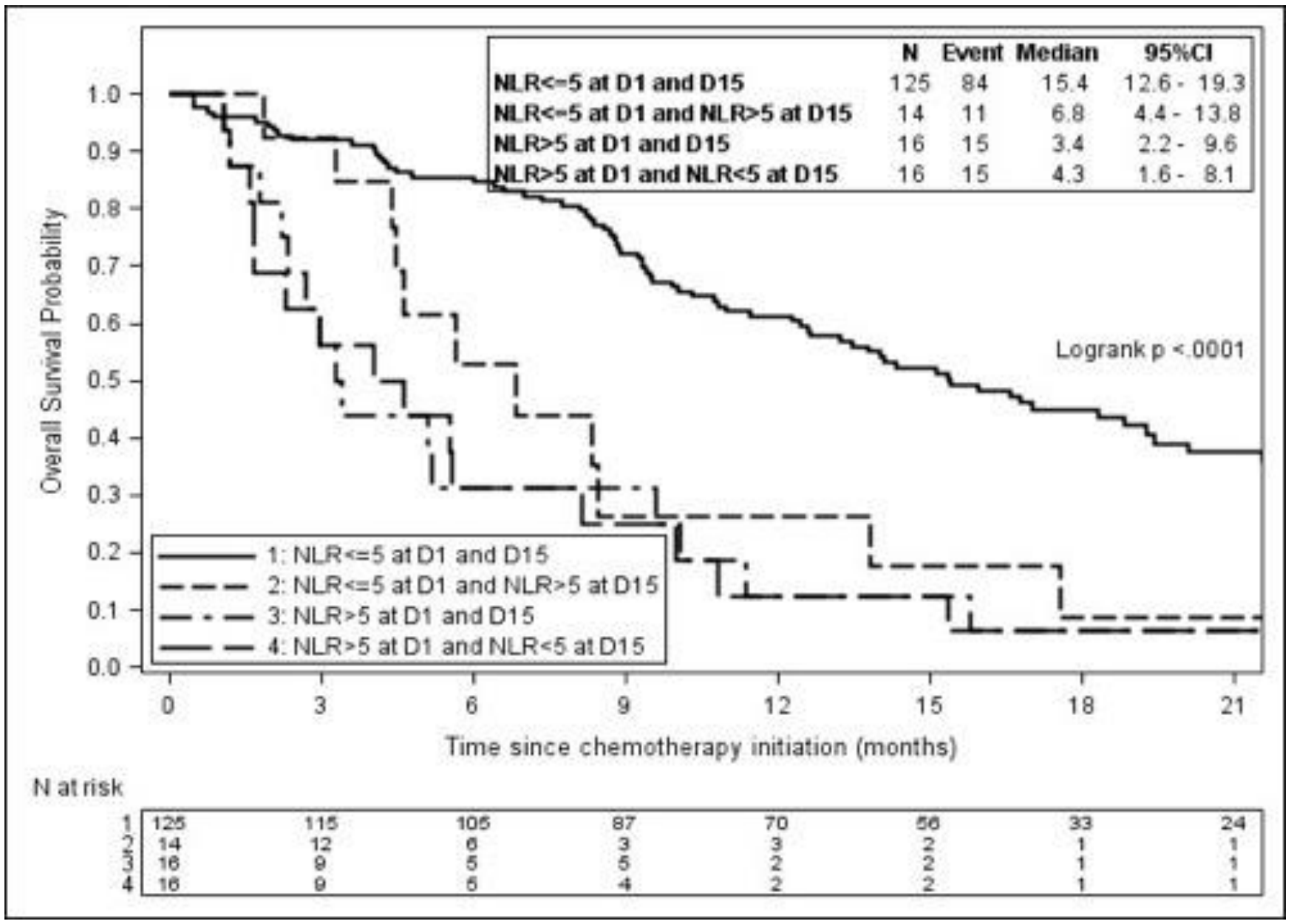


<smiles>CCC(CC)C(CC)CC</smiles> 


\begin{abstract}
APPENDICES
Paul McLellan, Sorbonne Université, Paris, France; Department of Hepato-Gastroenterology, Groupe Hospitalier Pitié Salpêtrière, Paris; France. Email: paul.mclellan@ hotmail.fr

Jean Baptiste Bachet, Sorbonne Université, Paris, France; Department of HepatoGastroenterology, Groupe Hospitalier Pitié Salpêtrière, Paris; France. Email: jeanbaptiste.bachet@aphp.fr
\end{abstract}




\author{
Abbreviations \\ ECOG PS: Eastern Cooperative Oncology Group Performance Status \\ CA 19-9: Carbohydrate antigen 19-9 \\ CEA: Carcinoembryonic antigen \\ NLR: Neutrophil to lymphocyte ratio \\ OS: Overall survival \\ PFS: Progression-free survival \\ HR: Hazard ratio \\ CI: Confidence interval \\ GHPS: Pitié-Salpêtrière Hospital Group \\ IQR: Interquartile range
}


Table A.1. Comparison of baseline characteristics between the two cohorts of patients

Table A.2. Comparison of characteristics between patients with and without NLR data at baseline

Table A.3. Univariate Cox proportional hazards model for progression-free survival

Table A.4. Multivariate Cox proportional hazards model for progression-free survival

Table A.5. Comparison of characteristics between patients with and without NLR data at baseline in the AFUGEM cohort

Table A.6. Comparison of characteristics between patients with and without NLR data at baseline in the GHPS cohort

Table A.7. Comparison of patient characteristics according to NLR at baseline in the AFUGEM cohort

Table A.8. Comparison of patient characteristics according to NLR at baseline in the GHPS cohort

Table A.9. Chemotherapy regimen in the GHPS cohort $(n=145)$

Table A.10. Dosage of different chemotherapy regimens

Table A.11. Inclusion and exclusion criteria in the AFUGEM phase II trial

Table A12. Evaluation of prognostic value of NLR evolution between baseline and Day 15, and between baseline and Day 30 . 
Figure A.1. Overall survival in the both study cohorts

Figure A.2. Progression-free survival in the both study cohorts

Figure A.3. Overall survival according to availability of NLR at baseline

Figure A.4. Progression-free survival according to availability of NLR at baseline

Figure A.5. Relation between overall survival and NLR using a restricted cubic spline method

Figure A.6. Overall survival according to a NLR baseline cut-off of 5

Figure A.7. Progression-free survival according to a NLR baseline cut-off of 5

Figure A.8. Overall survival according to a NLR baseline cut-off of 5 (after exclusion of the 10 patients with ECOG PS 3)

Figure A.9. Progression-free survival according to a NLR baseline cut-off of 5 (after exclusion of the 10 patients with ECOG PS 3)

Figure A.10. Progression-free survival according to NLR at baseline and to NLR on day 15 of cycle

Figure A11. Overall survival according to NLR at baseline and NLR on day 15 of cycle (after exclusion of the 10 patients with ECOG PS 3)

Figure A12. Progression-free survival according to NLR at baseline and NLR on day 15 of cycle (after exclusion of the 10 patients with ECOG PS 3)

Figure A13. Overall survival according to NLR at baseline in A) the AFUGEM cohort and B) the GHPS cohort

Figure A14. Progression-free survival according to NLR at baseline in A) the AFUGEM cohort and B) the GHPS cohort

Figure A15. Overall survival according to NLR on day 1 and day 15 of cycle in A) the AFUGEM cohort and B) the GHPS cohort

Figure A16. Progression-free survival according to NLR on day 1 and day 15 of cycle in A) the AFUGEM cohort and B) the GHPS cohort

Figure A17. Evolution of NLR over time in A) the AFUGEM cohort and B) the GHPS cohort

Figure A18. Overall survival in patients with baseline NLR $<5$ according to the presence of ctDNA in the GHPS cohort 
Figure A19. Progression-free survival in patients with baseline NLR $<5$ according to the presence of ctDNA in the GHPS cohort 
Table A1. Comparison of baseline characteristics between the two cohorts of patients

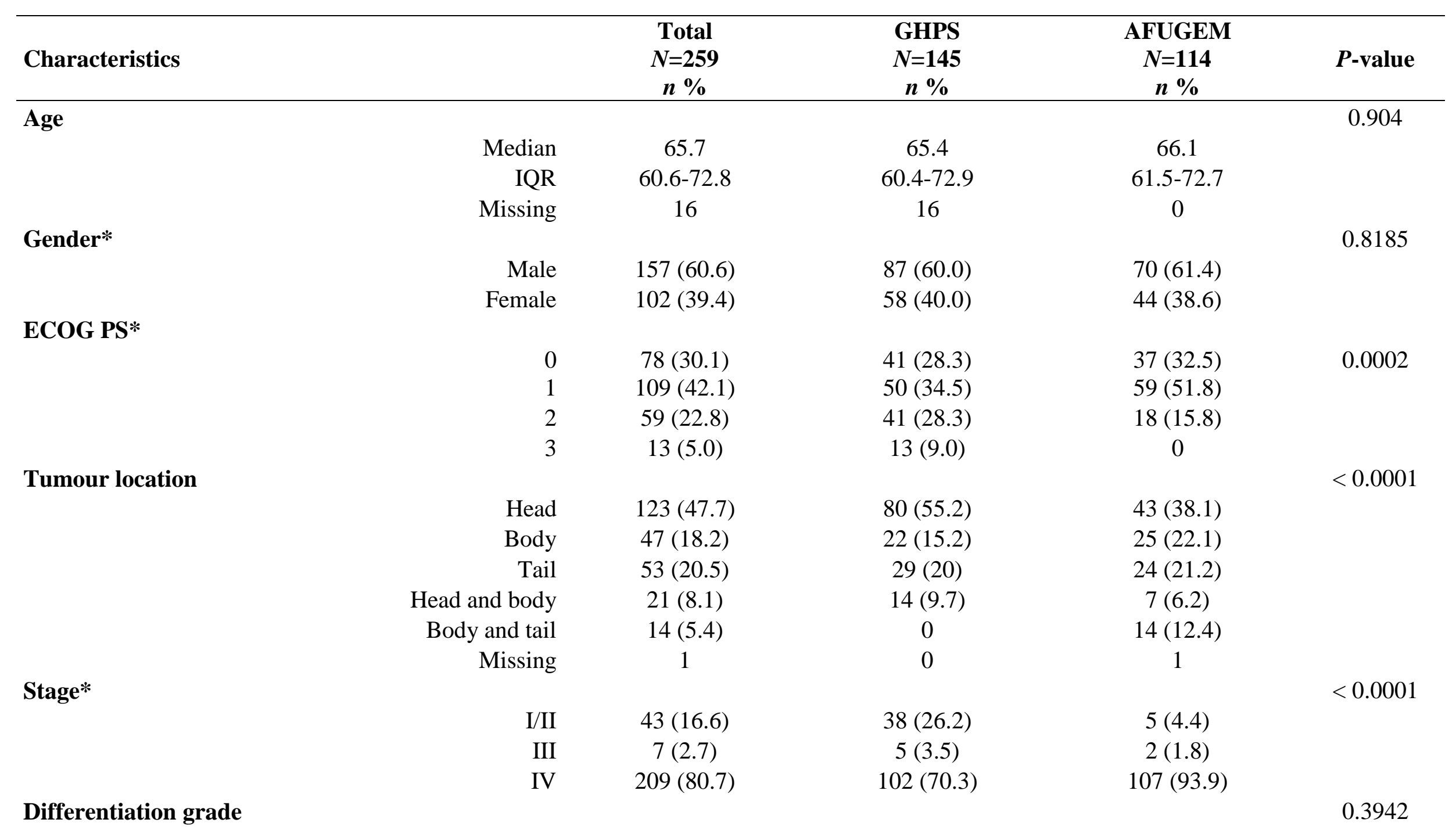


Number of metastatic sites

Liver metastases*

Resection of primary tumour*

\section{Adjuvant chemotherapy}

Albumin (g/l)

CA 19-9 (UI/ml)

CEA (ng/ml)

NLR at baseline

$\begin{array}{rc}\text { Well } & 74(35.8) \\ \text { Moderate } & 103(49.8) \\ \text { Poor } & 30(14.5) \\ \text { Missing } & 55\end{array}$

$51(38.1)$

$62(46.3)$

$21(15.7)$

11
84 (58.7)
$59(41.3)$
2

Missing

$$
101 \text { (39.3) }
$$

2

$$
\begin{gathered}
162(62.6) \\
64(24.7) \\
44(17.2) \\
3 \\
37 \\
32-40.5 \\
15
\end{gathered}
$$

Missing

Median

IQR

Missing

$$
\begin{array}{r}
\text { Median } \\
\text { IQR } \\
\text { Missing }
\end{array}
$$

Median

IQR

Missing

Median
IQR
496

$39.8-4413.0$

18

5.4

2.3-19.6

20

2.9

1.9-4.9
76 (52.4)

$49(33.8)$

39 (26.9)

0

36

30-39

15

355

29-2555.5

9

4.5

2-18

9

2.8

$1.9-4.9$
23 (31.5)

$41(56.2)$

9 (12.3)

41

$$
72(63.2)
$$

$42(36.8)$

0

0.1558

86 (75.4)

15 (13.2)

5 (4.5)

3

38.2

34-42

0

891

65-9205

9

6.0

2.5-23

11

3.0

1.9-4.9

0.4714

0.0001

0.0001

$<0.0001$

0.0021

0.0093 


\begin{tabular}{|c|c|c|c|c|c|}
\hline & Missing & 47 & 18 & 29 & \\
\hline Death & & $182(70.3)$ & $103(71.0)$ & $79(73.8)$ & 0.7615 \\
\hline Progression & & $145(56.0)$ & $83(57.2)$ & $62(54.4)$ & 0.6458 \\
\hline \multicolumn{6}{|l|}{ OS in months } \\
\hline & Median 95\% CI & $10.32(9.3-12.6)$ & $10.32(8.4-13.8)$ & $10.02(8.8-13.6)$ & 0.8061 \\
\hline \multicolumn{6}{|l|}{ PFS in months } \\
\hline & Median 95\% CI & $5.29(4.4-6.1)$ & $4.57(3.3-5.6)$ & $6.41(4.8-7.7)$ & 0.8121 \\
\hline \multicolumn{6}{|l|}{ Follow-up in months } \\
\hline & Median 95\% CI & $19.35(17.3-23.6)$ & $31.38(24.4-61.6)$ & $16.89(15.5-17.9)$ & 0.0119 \\
\hline
\end{tabular}

*no missing data

Abbreviations: IQR=interquartile range; ECOG PS=Eastern Cooperative Oncology Group Performance Status; CA 19-9=carbohydrate antigen; $\mathrm{CEA}=$ Carcinoembryonic antigen; NLR=neutrophil-to-lymphocyte ratio; OS=overall survival; $\mathrm{PFS}=$ progression-free survival 
Table A2. Comparison of characteristics between patients with and without NLR data at baseline

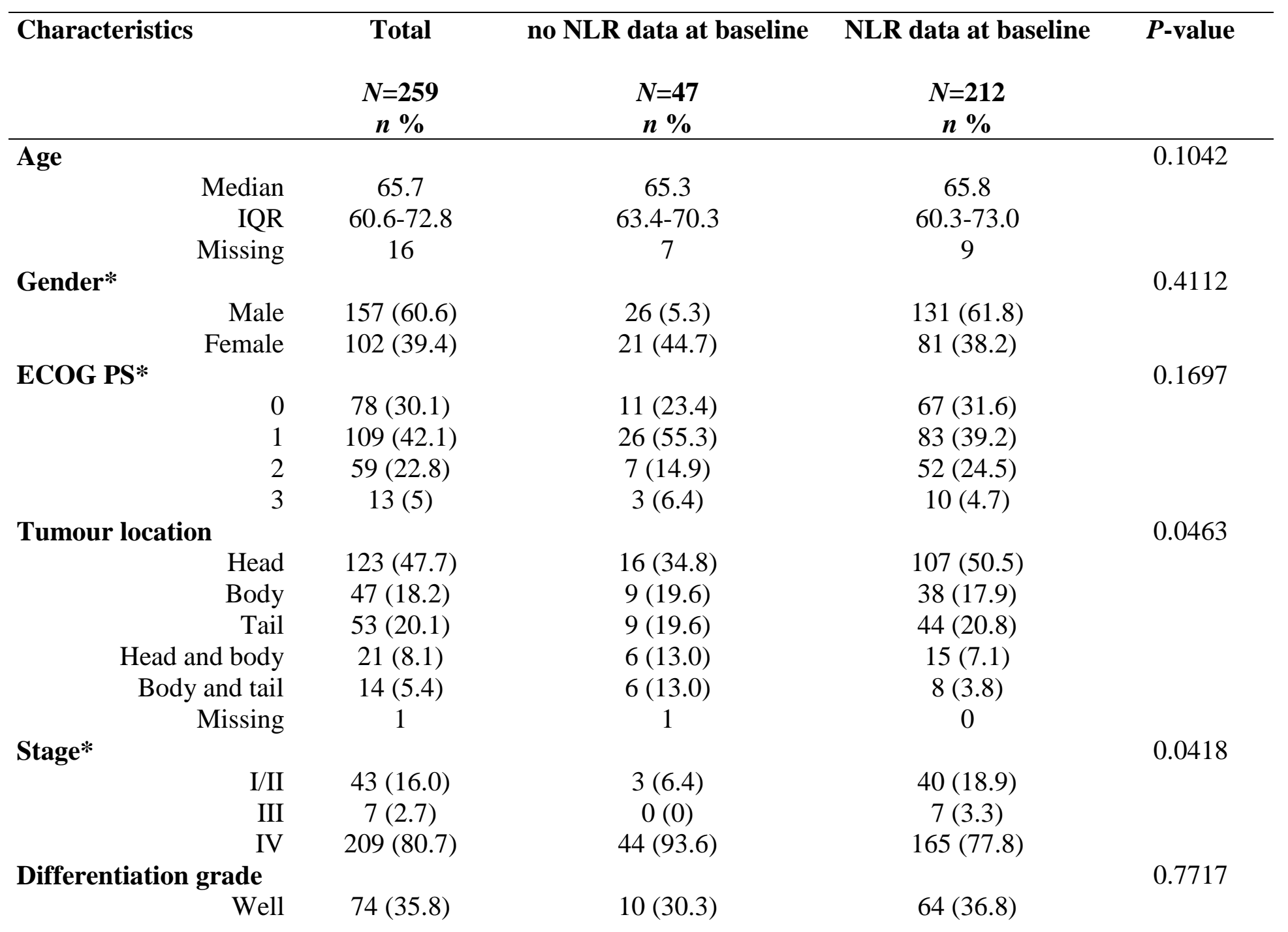




$\begin{array}{rccc}\text { Moderate } & 103(49.8) & 18(54.6) & 85(48.9) \\ \text { Poor } & 30(14.5) & 5(15.2) & 25(14.4) \\ \text { Missing } & 55 & 14 & 38\end{array}$

Number of metastatic

sites

1
Missing
Liver metastases*

$$
156(60.7)
$$$$
101(39.3)
$$$$
2
$$

$162(62.6)$

Resection of primary

$64(24.7)$

Adjuvant

chemotherapy

$\begin{array}{lrc} & \text { Yes } & 44(17.2) \\ \text { Albumin (g/l) } & \text { Missing } & 3 \\ & & \\ & \text { Median } & 37 \\ & \text { IQR } & 32-40.5 \\ \text { Missing } & 15\end{array}$

CA 19-9 (UI/ml)

$\begin{array}{rc}\text { Median } & 496 \\ \text { IQR } & 39.8-4413.0\end{array}$

CEA (ng/ml)

Missing 18

$\begin{array}{rc}\text { Median } & 5.4 \\ \text { IQR } & 2.3-19.6\end{array}$

Missing

20

Cohort*

$$
\text { AFUGEM } 114 \text { (44.0) }
$$

29 (61.7)

$25(53.2)$

$22(46.8)$

0

$24(51.1)$

$5(10.7)$

0.2436

$131(62.4)$

79 (37.6)

2

$138(65.1) \quad 0.0722$

$59(27.8) \quad 0.0134$

0.0919

4 (8.7)

1

35

30.4-39

4

968.2

64.8-14000

3

8.8

2.7-45.3

3

0.0069

85 (40.1) 

GHPS
$145(55.9)$
$18(38.3)$
$127(59.9)$

\begin{tabular}{|c|c|c|c|c|}
\hline Death & $182(70.3)$ & $31(66.0)$ & $151(71.2)$ & 0.4746 \\
\hline Progression & $145(56.0)$ & $25(53.2)$ & $120(56.6)$ & 0.6698 \\
\hline OS in months & & & & \\
\hline Median 95\% CI & $10.32(9.3-12.6)$ & $9.89(6.7-15.3)$ & $10.74(8.9-13.3)$ & 0.7894 \\
\hline PFS in months & & & & \\
\hline Median 95\% CI & $5.29(4.4-6.1)$ & $4.37(2.3-7.1)$ & $5.36(4.4-6.2)$ & 0.7104 \\
\hline
\end{tabular}

\section{(1)}

*No missing data

Abbreviations: IQR= interquartile range; ECOG PS=Eastern Cooperative Oncology Group Performance Status; CA 19-9=carbohydrate antigen;

$\mathrm{CEA}=$ carcinoembryonic antigen; NLR=neutrophil-to-lymphocyte ratio; OS=overall survival; PFS=progression-free survival 
Table A3. Univariate Cox proportional hazards model for progression-free survival

\begin{tabular}{|c|c|c|c|c|c|}
\hline & & $N$ (events) & HR & $95 \% \mathrm{CI}$ & $P$-value \\
\hline \multirow[t]{2}{*}{ Gender } & Male & $131(112)$ & 1 & & 0.1314 \\
\hline & Female & $81(61)$ & 0.79 & $0.58-1.08$ & \\
\hline \multirow[t]{2}{*}{ ECOG PS } & $0-1$ & $150(123)$ & 1 & & $<0.0001$ \\
\hline & $2-3$ & $62(50)$ & 2.06 & $1.48-2.88$ & \\
\hline \multirow{2}{*}{$\begin{array}{l}\text { Primary tumour } \\
\text { location }\end{array}$} & Head/Head and body & $122(95)$ & 1 & & 0.0024 \\
\hline & Other & $90(78)$ & 1.6 & $1.18-2.16$ & \\
\hline \multirow[t]{2}{*}{ Age } & $<65$ years & $90(74)$ & 1 & & 0.0465 \\
\hline & $\geq 65$ years & $113(99)$ & 1.36 & $1.00-1.85$ & \\
\hline \multirow[t]{2}{*}{ Stage } & IV & $45(35)$ & 1 & & 0.0183 \\
\hline & I-III & $158(138)$ & 0.63 & $0.43-0.93$ & \\
\hline \multirow[t]{2}{*}{ Differentiation grade } & Poor and moderate & $110(95)$ & 1 & & 0.0072 \\
\hline & Well & $64(50)$ & 0.62 & $0.44-0.88$ & \\
\hline \multirow{3}{*}{$\begin{array}{l}\text { Number of metastatic } \\
\text { sites }\end{array}$} & 1 & $131(107)$ & 1 & & 0.1152 \\
\hline & 2 & $58(49)$ & 1.16 & $0.82-1.62$ & \\
\hline & $\geq 3$ & $21(16)$ & 1.74 & $1.02-2.96$ & \\
\hline \multirow[t]{2}{*}{ Liver metastases } & Yes & $132(116)$ & 1 & & 0.2177 \\
\hline & No & $71(57)$ & 0.82 & $0.60-1.13$ & \\
\hline \multirow{2}{*}{$\begin{array}{l}\text { Resection of primary } \\
\text { tumour }\end{array}$} & No & $153(129)$ & 1 & & 0.0127 \\
\hline & Yes & $59(44)$ & 0.64 & $0.45-0.91$ & \\
\hline \multirow{2}{*}{$\begin{array}{l}\text { Adjuvant } \\
\text { chemotherapy }\end{array}$} & No & $163(141)$ & 1 & & 0.3235 \\
\hline & Yes & $38(31)$ & 0.82 & $0.56-1.21$ & \\
\hline \multirow[t]{2}{*}{ Albumin (g/l) } & $<40$ & $132(111)$ & 1 & & 0.0012 \\
\hline & $\geq 40$ & $69(53)$ & 0.58 & $0.42-0.81$ & \\
\hline \multirow[t]{2}{*}{ CEA (ng/ml) } & $<8$ & $115(96)$ & 1 & & 0.0585 \\
\hline & $\geq 8$ & $80(64)$ & 1.36 & $0.99-1.87$ & \\
\hline CA19-9 (UI/ml) & $<1000$ & $120(94)$ & 1 & & 0.0073 \\
\hline
\end{tabular}




\begin{tabular}{llcccc} 
& $\geq 1000$ & $77(67)$ & 1.55 & $1.12-2.12$ & \\
NLR at baseline & $\leq 5$ & $162(130)$ & 1 & & $<0.0001$ \\
& $>5$ & $50(43)$ & 2.38 & $1.67-3.38$ & \\
\hline
\end{tabular}

Abbreviations: ECOG PS=Eastern Cooperative Oncology Group Performance Status; CA 19-9=carbohydrate antigen; CEA=carcinoembryonic antigen; NLR=neutrophil-to-lymphocyte ratio 
Table A4. Multivariate Cox proportional hazards model for progression-free survival

\begin{tabular}{|c|c|c|c|c|c|}
\hline & & $N$ (events) & HR & $95 \% \mathrm{CI}$ & $P$-value \\
\hline & & $188(153)$ & & & \\
\hline \multirow[t]{2}{*}{ NLR at baseline } & $\leq 5$ & & 1 & & 0.0026 \\
\hline & $>5$ & & 1.80 & $1.23-2.65$ & \\
\hline \multirow{3}{*}{$\begin{array}{l}\text { Primary tumour } \\
\text { location }\end{array}$} & Head/Hea & & & & \\
\hline & and body & & 1 & & 0.0019 \\
\hline & Other & & 1.70 & $1.22-2.37$ & \\
\hline \multirow{2}{*}{ Albumin (g/l) } & $<40$ & & 1 & & 0.0003 \\
\hline & $\geq 40$ & & 0.52 & $0.37-0.74$ & \\
\hline \multirow{2}{*}{ CA19-9 (UI/ml) } & $<1000$ & & 1 & & 0.0205 \\
\hline & $\geq 1000$ & & 1.49 & $1.06-2.08$ & \\
\hline
\end{tabular}

Abbreviations: CA 19-9=carbohydrate antigen; NLR=neutrophil-to-lymphocyte ratio 
Table A5. Comparison of characteristics between patients with and without NLR data at baseline in the AFUGEM cohort

\begin{tabular}{|c|c|c|c|c|}
\hline \multirow[t]{2}{*}{ Characteristics } & Total & $\begin{array}{l}\text { no NLR data } \\
\text { at baseline }\end{array}$ & $\begin{array}{c}\text { NLR } \\
\text { information at } \\
\text { baseline }\end{array}$ & $P$-value \\
\hline & $\begin{array}{c}N=114 \\
n(\%)\end{array}$ & $\begin{array}{l}N=29 \\
n(\%)\end{array}$ & $\begin{array}{l}N=85 \\
n(\%)\end{array}$ & \\
\hline Age* $^{*}$ & & & & 0.3488 \\
\hline Median & 66.1 & 64.4 & 66.4 & \\
\hline IQR & $61.5-72.7$ & $62.9-70.2$ & $61.3-73.1$ & \\
\hline Min-max & $45.0-85.7$ & $45.0-85.0$ & $46.6-85.7$ & \\
\hline Missing & 0 & 0 & 0 & \\
\hline Gender & & & & 0.7215 \\
\hline Male & $70(61.4)$ & $17(58.6)$ & $53(62.3)$ & \\
\hline Female & $44(38.6)$ & $12(41.4)$ & $32(37.7)$ & \\
\hline ECOG PS & & & & 0.0075 \\
\hline 0 & $37(32.5)$ & $6(20.7)$ & $31(36.5)$ & \\
\hline 1 & $59(51.8)$ & $22(75.9)$ & $37(43.5)$ & \\
\hline 2 & $18(15.8)$ & $1(3.5)$ & $17(20.0)$ & \\
\hline 3 & 0 & 0 & 0 & \\
\hline Tumour location & & & & 0.2311 \\
\hline Head & $43(38.1)$ & $6(21.4)$ & $37(43.5)$ & \\
\hline Body & $25(22.1)$ & $7(25.0)$ & $18(21.2)$ & \\
\hline Tail & $24(21.2)$ & $7(25.0)$ & $17(20.0)$ & \\
\hline Head and body & $7(6.2)$ & $2(7.1)$ & $5(5.9)$ & \\
\hline Body and tail & $14(12.4)$ & $6(21.4)$ & $8(9.4)$ & \\
\hline Missing & 1 & 1 & 0 & \\
\hline
\end{tabular}


Stage

$5(4.4)$
$2(1.8)$
$107(93.9)$

$1(3.5)$
0
$28(96.6)$

$2(13.3)$
$11(73.3)$
$2(13.3)$
14

$$
\begin{gathered}
4(4.7) \\
2(2.4) \\
79(92.9)
\end{gathered}
$$

\section{Differentiation grade}

$$
\text { Well }
$$

$$
\begin{aligned}
& 23(31.5) \\
& 41(56.2)
\end{aligned}
$$$$
9(12.3)
$$$$
41
$$

Metastatic site

$$
\text { Missing }
$$

1
$\geq 2$
Liver metastases$$
72(63.2)
$$$$
42(36.9)
$$$$
86(75.4)
$$

Resection of primary

tumour

15 (13.2)

Adjuvant chemotherapy

$$
\text { Yes }
$$

Missing

Albumin (g/l)

$$
\begin{array}{r}
\text { Median } \\
\text { IQR }
\end{array}
$$

CA 19-9 (UI/ml)

$$
\begin{array}{r}
\text { Median } \\
\text { IQR }
\end{array}
$$

CEA (ng/ml)

$$
\text { Median }
$$

IQR

Treatment arm

Gemcitabine plus nab-paclitaxel

$$
1 \text { (3.5) }
$$$$
1(3.6)
$$$$
1
$$

53 (62.4)

$32(37.7)$

65 (76.5)

14 (16.5)

.6612

0.7603

$4(4.8)$

$4(4.8)$

2

36

33.2-40

39.3

34.7-42

$$
1375.5
$$

812.4

50.2-9205

6

2.5-23

186.3-9928.5

5.5

2.5-19.6

2.7-47.4$$
0.454
$$

0.3839

$39(34.2)$

8 (27.6)

31 (36.5) 
Simplified leucovorin and fluorouracil plus nab-paclitaxel

$$
75(65.8) \quad 21(72.4) \quad 54(63.5)
$$

\begin{tabular}{lcccc} 
Death & $79(69.30)$ & $21(72.41)$ & $58(68.24)$ & 0.6736 \\
$\begin{array}{l}\text { Progression } \\
\text { OS in months }\end{array}$ & $62(54.4)$ & $18(62.1)$ & $44(51.8)$ & 0.336 \\
$\quad \begin{array}{l}\text { Median 95\% CI } \\
\text { PFS in months }\end{array}$ & $10.02(8.8-13.6)$ & $9.49(5.9-16.4)$ & $10.81(8.8-14.1)$ & 0.7587 \\
$\quad$ & & & & \\
$\quad$ Median 95\% CI & $6.41(4.8-7.7)$ & $4.86(1.9-8)$ & $7.20(4.9-8.1)$ & 0.2727 \\
\hline
\end{tabular}

Abbreviations: IQR= interquartile range; ECOG PS=Eastern Cooperative Oncology Group Performance Status; CA 19-9=carbohydrate antigen; $\mathrm{CEA}=$ carcinoembryonic antigen; NLR=neutrophil-to-lymphocyte ratio; OS=overall survival; PFS=progression-free survival 
Table A6. Comparison of characteristics between patients with and without NLR data at baseline in the GHPS cohort

\begin{tabular}{|c|c|c|c|c|}
\hline \multirow[t]{2}{*}{ Characteristics } & Total & $\begin{array}{c}\text { no NLR } \\
\text { information at } \\
\text { baseline }\end{array}$ & $\begin{array}{c}\text { NLR } \\
\text { information at } \\
\text { baseline }\end{array}$ & \multirow[t]{2}{*}{$P$-value } \\
\hline & $\begin{array}{c}N=145 \\
n \%\end{array}$ & $\begin{array}{c}N=18 \\
n \%\end{array}$ & $\begin{array}{c}N=127 \\
n \%\end{array}$ & \\
\hline Age* & & & & 0.2957 \\
\hline Median & 65.4 & 67.2 & 65.3 & \\
\hline IQR & $60.4-72.9$ & $64.5-73.2$ & $60.2-72.9$ & \\
\hline Gender & & & & 0.3548 \\
\hline Male & $87(60.0)$ & $9(50.0)$ & $78(61.4)$ & \\
\hline Female & $58(40.0)$ & $9(50.0)$ & $49(38.6)$ & \\
\hline ECOG PS & & & & 0.4857 \\
\hline 0 & $41(28.3)$ & $5(27.8)$ & $36(28.4)$ & \\
\hline 1 & $50(34.5)$ & $4(22.2)$ & $46(36.2)$ & \\
\hline 2 & $41(28.3)$ & $6(33.3)$ & $35(27.6)$ & \\
\hline 3 & $13(9.0)$ & $3(16.7)$ & $10(7.9)$ & \\
\hline Tumour location & & & & 0.2591 \\
\hline Head & $80(55.2)$ & $10(55.6)$ & $70(55.1)$ & \\
\hline Body & $22(15.2)$ & $2(11.1)$ & $20(15.8)$ & \\
\hline Tail & $29(20.0)$ & $2(11.1)$ & $27(21.2)$ & \\
\hline Head and body & $14(9.7)$ & $4(22.2)$ & $10(7.3)$ & \\
\hline Body and tail & 0 & 0 & 0 & \\
\hline Stage & & & & 0.2532 \\
\hline $\mathrm{I} / \mathrm{II}$ & $38(26.2)$ & $2(11.1)$ & $36(28.4)$ & \\
\hline III & $5(3.5)$ & 0 & $5(3.9)$ & \\
\hline IV & $102(70.3)$ & $16(88.9)$ & $86(67.7)$ & \\
\hline Differentiation & & & & 0.7864 \\
\hline
\end{tabular}




\begin{tabular}{|c|c|c|c|c|}
\hline Well & $51(38.1)$ & $8(44.4)$ & $43(37.1)$ & \\
\hline Moderate & $62(46.3)$ & 7 (38.9) & $55(47.4)$ & \\
\hline Poor & $21(15.7)$ & $3(16.7)$ & $18(15.5)$ & \\
\hline \multicolumn{4}{|l|}{ Metastatic site } & \multirow[t]{3}{*}{0.0192} \\
\hline 1 & $84(58.7)$ & $6(33.3)$ & $78(62.4)$ & \\
\hline$\geq 2$ & $59(41.3)$ & $12(66.7)$ & $47(37.6)$ & \\
\hline \multirow{2}{*}{$\begin{array}{l}\text { Liver metastases } \\
\text { Resection of } \\
\text { primary tumour }\end{array}$} & $76(52.4)$ & $3(16.7)$ & $73(57.5)$ & 0.0012 \\
\hline & $49(33.8)$ & $4(22.2)$ & $45(35.4)$ & 0.2674 \\
\hline Yes & 39 (26.9) & $3(16.7)$ & $36(28.4)$ & 0.3999 \\
\hline \multicolumn{4}{|l|}{ Albumin (g/l) } & \multirow[t]{3}{*}{0.0414} \\
\hline Median & 36 & 31.5 & 36.5 & \\
\hline IQR & $30-39$ & $27-37$ & $31-40$ & \\
\hline \multicolumn{4}{|l|}{ CA 19.9 (UI/ml) } & \multirow[t]{3}{*}{0.9327} \\
\hline Median & 355 & 213.5 & 369 & \\
\hline IQR & $29-2555.5$ & $10-18765$ & $31.5-2092$ & \\
\hline \multicolumn{4}{|l|}{ CEA (ng/ml) } & \multirow[t]{3}{*}{0.2671} \\
\hline Median & 4.5 & 6.5 & 4 & \\
\hline IQR & $2-18$ & $3-43.5$ & $2-17$ & \\
\hline Death & 1103 (71.03) & $10(55.6)$ & $93(73.2)$ & 0.1219 \\
\hline Progression & $83(57.2)$ & 7 (38.9) & $76(59.9)$ & 0.0926 \\
\hline \multicolumn{5}{|l|}{ OS } \\
\hline Median 95\%CI & $10.32(8.4-13.8)$ & $11.70(2.9-24.2)$ & $10.32(8.3-13.8)$ & 0.9578 \\
\hline \multicolumn{5}{|l|}{ PFS } \\
\hline Median 95\%CI & $4.57(3.3-5.6)$ & $3.29(2.4-19.3)$ & $4.60(3.3-5.6)$ & 0.5935 \\
\hline
\end{tabular}


Abbreviations: IQR= interquartile range; ECOG PS=Eastern Cooperative Oncology Group Performance Status; CA 19-9=carbohydrate antigen; $\mathrm{CEA}=$ carcinoembryonic antigen; NLR=neutrophil-to-lymphocyte ratio; $\mathrm{OS}=$ overall survival; $\mathrm{PFS}=$ progression-free survival 
Table A7. Comparison of patient characteristics according to NLR at baseline in the AFUGEM cohort

\begin{tabular}{|c|c|c|c|c|}
\hline Characteristics & $\begin{array}{l}\text { NLR data at baseline } \\
\qquad \begin{array}{c}N=85 \\
n \%\end{array}\end{array}$ & $\mathrm{NLR} \leq 5$ & $\mathbf{N L R}>5$ & $P$-value \\
\hline Age* & & & & 0.3949 \\
\hline Median & 66.3 & 66.1 & 68.6 & \\
\hline IQR & $61.3-73.1$ & $59.7-73.0$ & $62.54-73.11$ & \\
\hline Gender* & & & & 0.2771 \\
\hline Male & $53(62.3)$ & $42(65.6)$ & $11(52.9)$ & \\
\hline Female & $32(37.6)$ & $22(34.9)$ & $10(47.6)$ & \\
\hline ECOG PS* & & & & 0.0503 \\
\hline 0 & $31(36.5)$ & $26(40.6)$ & $5(23.8)$ & \\
\hline 1 & $37(43.5)$ & $29(45.3)$ & $8(38.1)$ & \\
\hline 2 & $17(20.0)$ & $9(14.1)$ & $8(38.1)$ & \\
\hline 3 & 0 & 0 & 0 & \\
\hline Tumour location & & & & 0.511 \\
\hline Head & $37(43.5)$ & $29(45.3)$ & $8(38.1)$ & \\
\hline Body & $18(21.2)$ & $11(17.2)$ & $7(33.3)$ & \\
\hline Tail & $17(20.0)$ & $13(20.3)$ & $4(19.0)$ & \\
\hline Head and body & $5(5.9)$ & $5(7.8)$ & 0 & \\
\hline Body and tail & $8(9.4)$ & $6(9.9)$ & $2(9.5)$ & \\
\hline Missing & 0 & 0 & 0 & \\
\hline Stage* & & & & 0.7559 \\
\hline $\mathrm{I} / \mathrm{II}$ & $4(4.7)$ & $4(6.2)$ & 0 & \\
\hline III & $2(2.3)$ & $2(3.1)$ & 0 & \\
\hline IV & $79(92.9)$ & $58(90.6)$ & $21(100)$ & \\
\hline Differentiation grade & & & & 0.0834 \\
\hline
\end{tabular}




\begin{tabular}{|c|c|c|c|c|}
\hline Well & $21(36.2)$ & $15(32.6)$ & $6(50.0)$ & \\
\hline Moderate & $30(51.7)$ & $27(58.7)$ & $3(25.0)$ & \\
\hline Poor & $7(12.1)$ & $4(8.7)$ & $3(25.0)$ & \\
\hline Missing & 27 & 18 & 9 & \\
\hline \multicolumn{4}{|l|}{ Metastatic site } & 0.6382 \\
\hline 1 & $53(62.3)$ & $39(60.9)$ & $14(66.7)$ & \\
\hline$\geq 2$ & $32(37.6)$ & $25(39.1)$ & $7(33.3)$ & \\
\hline Missing & 0 & 0 & 0 & \\
\hline & $65(76.5)$ & $50(78.1)$ & $15(71.4)$ & 0.5605 \\
\hline $\begin{array}{l}\text { Resection of primary } \\
\text { tumour* }\end{array}$ & $14(16.5)$ & $13(20.3)$ & $1(4.8)$ & 0.1721 \\
\hline \multicolumn{4}{|l|}{ Adjuvant chemotherapy } & 0.5678 \\
\hline Yes & $4(4.8)$ & $4(6.4)$ & 0 & \\
\hline Missing & 2 & 2 & 0 & \\
\hline \multicolumn{4}{|l|}{$\operatorname{Albumin}(g / L) *$} & 0.1735 \\
\hline Median & 39.3 & 40 & 37 & \\
\hline IQR & $34.68-42$ & $34.95-42.05$ & $31.72-40$ & \\
\hline \multicolumn{4}{|l|}{ CA $19.9(\mathrm{UI} / \mathrm{ml})$} & 0.263 \\
\hline Median & 812.4 & 561.7 & 2320.5 & \\
\hline IQR & $50.20-9205$ & $43-7477$ & $53.35-10453$ & \\
\hline Missing & 8 & 5 & 3 & \\
\hline \multicolumn{4}{|l|}{ CEA (ng/ml) } & 0.2627 \\
\hline Median & 5.5 & 5.36 & 8.6 & \\
\hline IQR & $2.5-19.6$ & $2.5-19.10$ & $3-112.2$ & \\
\hline Missing & 10 & 6 & 4 & \\
\hline \multicolumn{4}{|l|}{ Treatment* } & 0.7307 \\
\hline $\begin{array}{r}\text { Gemcitabine plus } \\
\text { nab-paclitaxel }\end{array}$ & $31(36.5)$ & $24(37.5)$ & $7(33.3)$ & \\
\hline
\end{tabular}




\begin{tabular}{|c|c|c|c|c|}
\hline $\begin{array}{r}\text { Simplified leucovorin } \\
\text { and fluorouracil plus } \\
\text { nab-paclitaxel }\end{array}$ & $54(63.5)$ & $40(62.5)$ & $14(66.7)$ & \\
\hline Death & $58(68.2)$ & $38(69.4)$ & $20(95.2)$ & 0.0022 \\
\hline Progression & $44(51.7)$ & $30(46.9)$ & $14(66.7)$ & 0.1153 \\
\hline \multicolumn{5}{|l|}{ OS in months } \\
\hline Median 95\%CI & $10.81(8.77-14.09)$ & $13.77(9.5-17.6)$ & $4.63(2.3-6.34)$ & $<0.0001$ \\
\hline \multicolumn{5}{|l|}{ PFS in months } \\
\hline Median 95\%CI & $7.20(4.93-8.12)$ & $8.21(7.2-10.3)$ & $2.33(1.6-4.0)$ & $<0.0001$ \\
\hline
\end{tabular}

*No missing data

Abbreviations: IQR= interquartile range; ECOG PS=Eastern Cooperative Oncology Group Performance Status; CA 19-9=carbohydrate antigen; $\mathrm{CEA}=$ carcinoembryonic antigen; NLR=neutrophil-to-lymphocyte ratio; $\mathrm{OS}=$ overall survival; $\mathrm{PFS}=$ progression-free survival 
Table A8. Comparison of patient characteristics according to NLR at baseline in the GHPS cohort

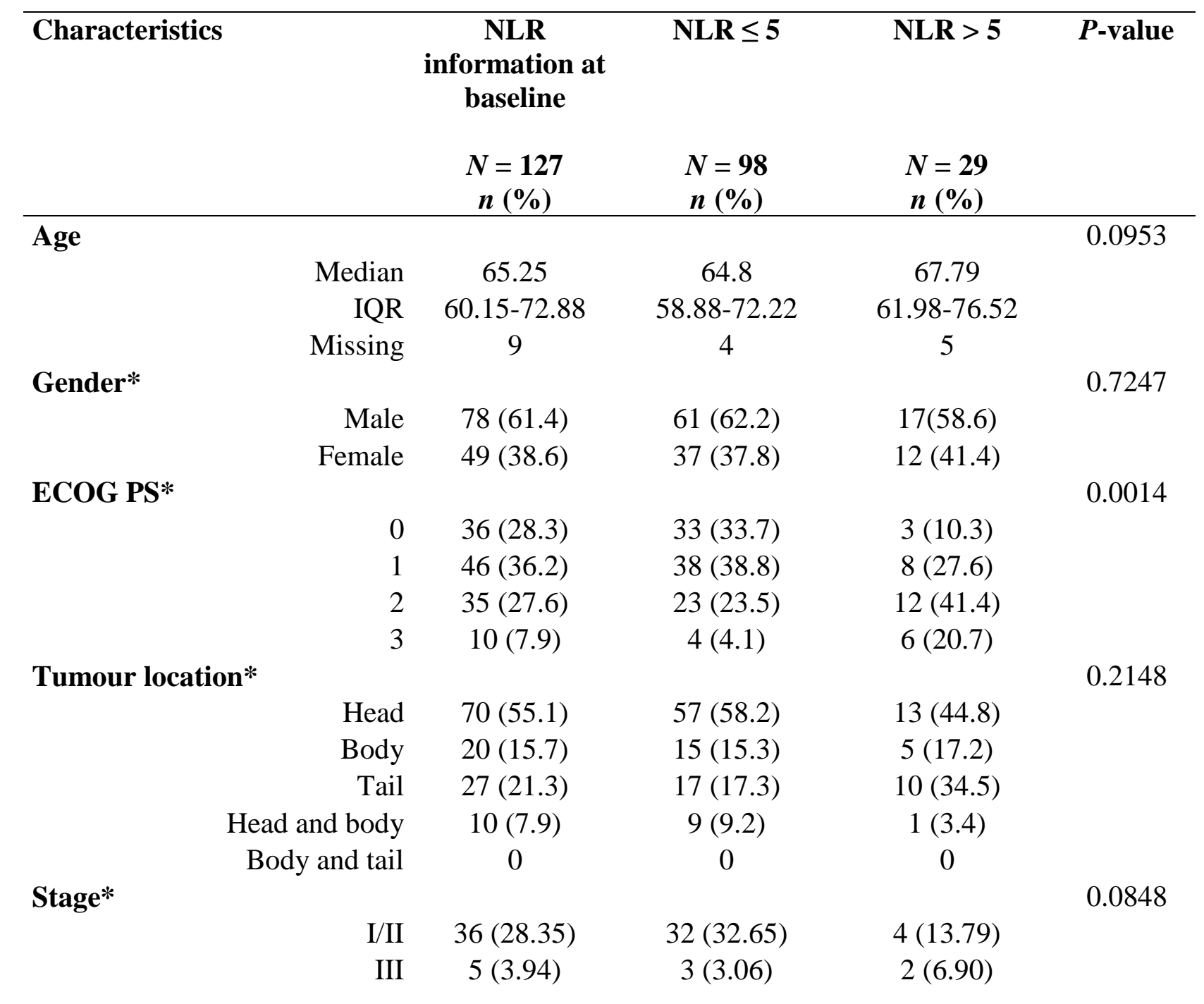




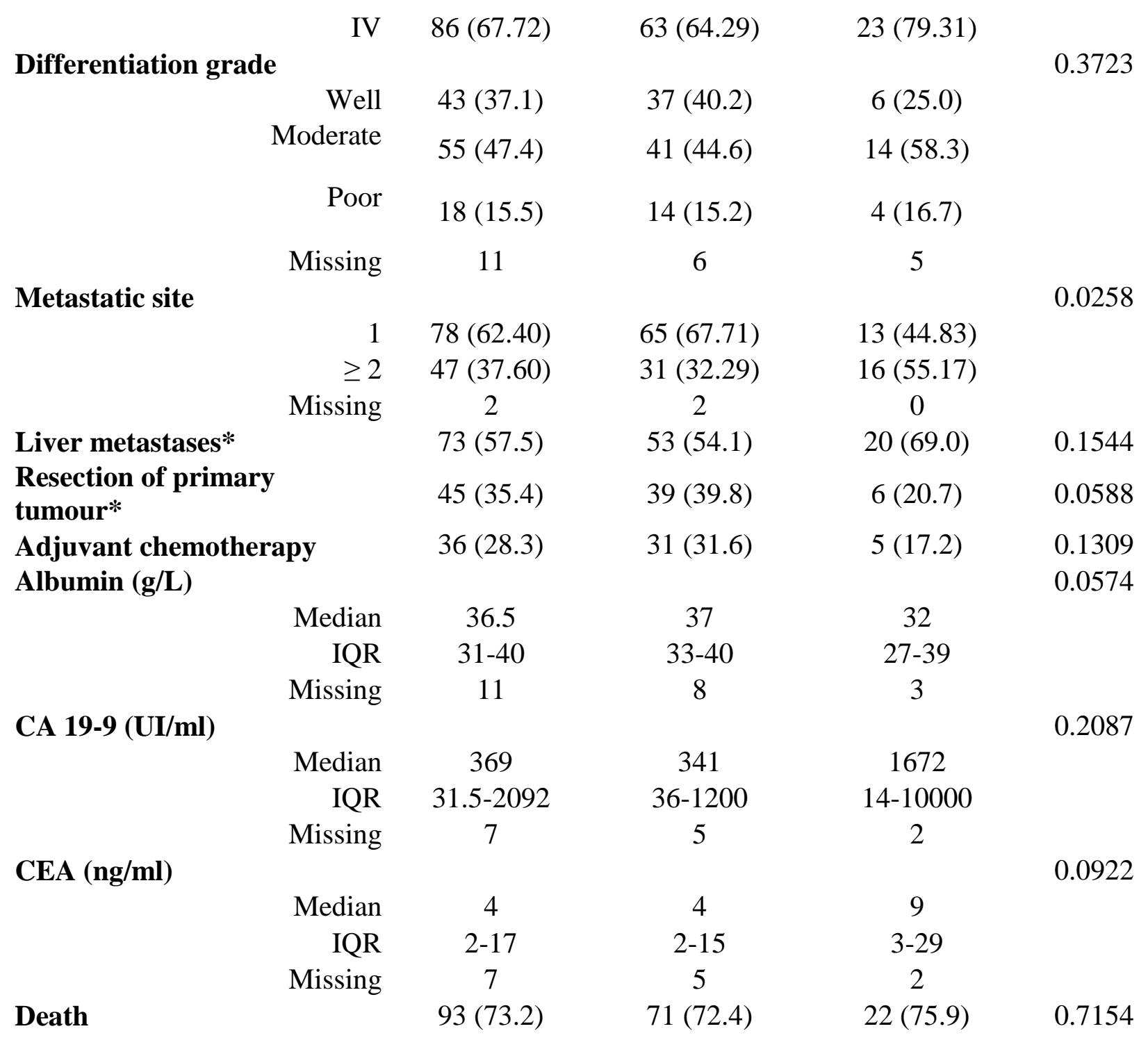




\begin{tabular}{|c|c|c|c|c|c|}
\hline Progression & & $76(59.8)$ & $68(69.4)$ & $8(27.6)$ & $<0.0001$ \\
\hline \multicolumn{6}{|c|}{ OS in months } \\
\hline & Median 95\% CI & $\begin{array}{c}10.32(8.4- \\
13.8)\end{array}$ & $\begin{array}{c}13.47(10.1- \\
18.3)\end{array}$ & $2.53(1.2-5.2)$ & $<0.0001$ \\
\hline \multicolumn{6}{|c|}{ PFS in months } \\
\hline & Median 95\% CI & $4.57(3.3-5.6)$ & $5.36(4.07-7.39)$ & $1.61(1.18-3.91)$ & 0.0124 \\
\hline
\end{tabular}

*No missing data

Abbreviations: IQR= interquartile range; ECOG PS=Eastern Cooperative Oncology Group Performance Status; CA 19-9=carbohydrate antigen; $\mathrm{CEA}=$ carcinoembryonic antigen; NLR=neutrophil-to-lymphocyte ratio; OS=overall survival; $\mathrm{PFS}=$ progression-free survival 
1 Table A9. Chemotherapy regimen in GHPS cohort $(n=145)$

2

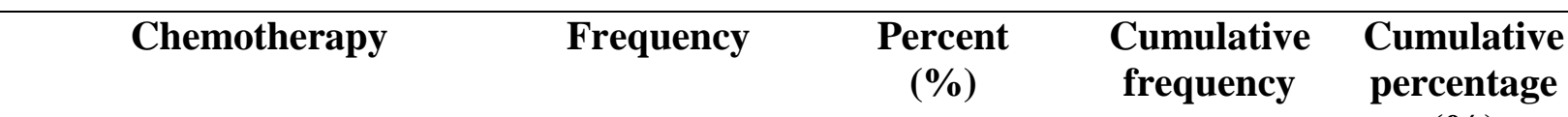

(\%)

\begin{tabular}{ccccc}
\hline None & 9 & 6.4 & 9 & 6.2 \\
Gemcitabine & 29 & 20.7 & 38 & 26.2 \\
Gemcitabine-Oxaliplatin & 2 & 1.4 & 40 & 27.6 \\
FOLFIRINOX & 47 & 33.6 & 87 & 60.0 \\
FOLFOX & 30 & 21.4 & 117 & 80.7 \\
FOLFIRI & 6 & 4.3 & 123 & 84.8 \\
Gemcitabine-Abraxane & 2 & 1.4 & 125 & 86.2 \\
5-FU-Abraxane & 5 & 3.6 & 130 & 89.7 \\
Gemcitabine-Erlotinib & 8 & 5.7 & 138 & 95.2 \\
Erlotinib & 1 & 0.7 & 139 & 95.9 \\
Maestro Trial & 1 & 0.7 & 140 & 96.6 \\
Missing & 5 & 3.6 & 145 & 100 \\
\hline
\end{tabular}


7 Table A10. Dosages of different chemotherapy regimens

\begin{tabular}{|c|c|}
\hline $\begin{array}{l}\text { Chemotherapy } \\
\text { regimens }\end{array}$ & Dosage \\
\hline $\begin{array}{l}\text { Gemcitabine } \\
\text { monotherapy }\end{array}$ & $\begin{array}{l}\text { - Gemcitabine: } 1000 \mathrm{mg} / \mathrm{m}^{2} \text {, days } 1,8,15 \\
\text { One cycle every } 4 \text { weeks }\end{array}$ \\
\hline $\begin{array}{l}\text { Gemcitabine and nab- } \\
\text { paclitaxel }\end{array}$ & $\begin{array}{l}\text { - Gemcitabine: } 1000 \mathrm{mg} / \mathrm{m}^{2} \text {, days } 1,8,15 \\
\text { - Nab-paclitaxel: } 125 \mathrm{mg} / \mathrm{m}^{2} \text {, days } 1,15 \text {, } \\
\text { One cycle every } 4 \text { weeks }\end{array}$ \\
\hline $\begin{array}{l}\text { 5-FU and nab- } \\
\text { paclitaxel }\end{array}$ & $\begin{array}{l}\text { - Nab-paclitaxel: } 125 \mathrm{mg} / \mathrm{m}^{2} \\
\text { - Leucovorin, } 400 \mathrm{mg} / \mathrm{m}^{2} \text { and } 5-\mathrm{FU}, 400 \mathrm{mg} / \mathrm{m}^{2} \text { given as a bolus } \\
\text { followed by } 2400 \mathrm{mg} / \mathrm{m}^{2} \text { given as a } 46-\text { hour continuous infusion } \\
\text { One cycle every } 2 \text { weeks }\end{array}$ \\
\hline $\begin{array}{l}\text { 5-FU, irinotecan, and } \\
\text { oxaliplatin }\end{array}$ & $\begin{array}{l}\text { - } \text { Oxaliplatin, } 85 \mathrm{mg} / \mathrm{m}^{2} \\
\text { - } \text { Irinotecan, } 180 \mathrm{mg} / \mathrm{m}^{2} \\
\text { - Leucovorin, } 400 \mathrm{mg} / \mathrm{m}^{2} \text { and } 5-\mathrm{FU}, 400 \mathrm{mg} / \mathrm{m}^{2} \text { given as a bolus } \\
\text { followed by } 2400 \mathrm{mg} / \mathrm{m}^{2} \text { given as a } 46-\text { hour continuous infusion } \\
\text { One cycle every } 2 \text { weeks }\end{array}$ \\
\hline 5-FU and irinotecan & $\begin{array}{l}\text { - Irinotecan, } 180 \mathrm{mg} / \mathrm{m}^{2} \\
\text { - Leucovorin, } 400 \mathrm{mg} / \mathrm{m}^{2} \text { and } 5-\mathrm{FU}, 400 \mathrm{mg} / \mathrm{m}^{2} \text { given as a bolus } \\
\text { followed by } 2400 \mathrm{mg} / \mathrm{m}^{2} \text { given as a } 46-\text { hour continuous infusion } \\
\text { One cycle every } 2 \text { weeks }\end{array}$ \\
\hline
\end{tabular}




\begin{tabular}{|l|l|}
\hline \multirow{5}{*}{ 5-FU and oxaliplatin } & $\begin{array}{l}\bullet \text { Oxaliplatin, } 85 \mathrm{mg} / \mathrm{m}^{2} \\
\text { - }\end{array}$ \\
& $\begin{array}{l}\text { Leucovorin, } 400 \mathrm{mg} / \mathrm{m}^{2} \text { and } 5-\mathrm{FU}, 400 \mathrm{mg} / \mathrm{m}^{2} \text { given as a bolus } \\
\text { followed by } 2400 \mathrm{mg} / \mathrm{m}^{2} \text { given as a } 46-h o u r \text { continuous infusion }\end{array}$ \\
& One cycle every 2 weeks
\end{tabular}

10 Abbreviations: 5-FU = 5-fluorouracil 
21 Table A11. Inclusion and exclusion criteria in the AFUGEM phase II trial

\begin{tabular}{|c|c|}
\hline & $\begin{array}{l}\text { 1. Signed and dated informed consent, } \\
\text { 2. Patients willing and able to comply with protocol requirements, } \\
\text { 3. Histologically or cytologically proven adenocarcinoma of the pancreas, } \\
\text { 4. Stage IV disease, } \\
\text { 5. No prior therapy for metastatic disease (in case of previous adjuvant therapy, } \\
\text { interval between the end of chemotherapy and relapse must be }>12 \text { months), } \\
\text { 6. At least one measurable or evaluable lesion as assessed by CT-scan or MRI } \\
\text { according to RECIST v1.1, } \\
\text { 7. Age } \geq 18 \text { years, } \\
\text { 8. ECOG PS } 0 \text { and } 2 \text {, } \\
\text { 9. Adequate hematologic function: neutrophils }>1.5 \times 10^{9} / \mathrm{L} \text {; platelets }>100 \times 10^{9} / \mathrm{L} \text {; } \\
\text { haemoglobin } \geq 9 \mathrm{~g} / \mathrm{dL} \text {, } \\
\text { 10.Adequate renal function: serum creatinine level }<150 \mu \mathrm{M} \text {, } \\
\text { 11.Adequate liver function: AST (SGOT) and } \mathrm{ALT}(\mathrm{SGPT}) \leq 2.5 \times \mathrm{ULN}(\leq 5 \times \mathrm{ULN}\end{array}$ \\
\hline
\end{tabular}




\begin{tabular}{|c|c|}
\hline & $\begin{array}{l}\text { in case of liver metastases), total bilirubin } \leq 1.5 \mathrm{x} \text { ULN, albumin } \geq 25 \mathrm{~g} / \mathrm{L} \text {, } \\
\text { 12.Baseline evaluations performed before randomization: clinical and blood } \\
\text { evaluations no more than } 14 \text { days prior to randomization, tumour assessment (CT- } \\
\text { scan or MRI, evaluation of nonmeasurable lesions) no more than } 21 \text { days prior to } \\
\text { randomization, } \\
\text { 13.Female patients must be surgically sterile, or be postmenopausal, or must commit } \\
\text { to using reliable and appropriate methods of contraception during the study and } \\
\text { during at least } 6 \text { months after the end of study treatment (when applicable). All } \\
\text { female patients with reproductive potential must have a negative pregnancy test ( } \beta \\
\text { HCG) within } 72 \text { h prior to starting nab-paclitaxel treatment. Breastfeeding is not } \\
\text { allowed. Male patients must agree to use effective contraception in addition to having } \\
\text { their partner use a contraceptive method as well during the trial and during at least } 6 \\
\text { months after the end of the study treatment, } \\
\text { 14.Registration with the French National Health Care System. }\end{array}$ \\
\hline & $\begin{array}{l}\text { 1. Medical history or evidence of CNS metastasis upon physical examination, unless } \\
\text { adequately treated (e.g., non-irradiated CNS metastasis, seizure not controlled with }\end{array}$ \\
\hline
\end{tabular}




\begin{tabular}{|l|l|}
$\mid \begin{array}{l}\text { 2. Local or locally advanced disease (stage I to III), } \\
\text { 3. Treatment with warfarin, } \\
\text { 4. Uncontrolled hypercalcemia, } \\
\text { 5. Pre-existing permanent neuropathy (NCI CTCAE grade } \geq 2), \\
\text { 6. Known dihydropyrimidine dehydrogenase deficiency, } \\
\text { 7. Concomitant unplanned antitumor therapy (e.g., chemotherapy, molecular targeted } \\
\text { therapy, immunotherapy), } \\
\text { 8. Treatment with any other investigational medicinal product within } 28 \text { days prior to } \\
\text { study entry, } \\
\text { 9. Other serious and uncontrolled non-malignant disease (e.g., active infection } \\
\text { requiring systemic therapy, coronary stenting or myocardial infarction, or stroke in } \\
\text { the past } 6 \text { months), } \\
\text { 10. HIV-infected patients or otherwise known to be HIV-positive with untreated } \\
\text { hepatitis B or hepatitis C, } \\
\text { 11. Medical history or active interstitial lung disease, }\end{array}$ \\
\hline
\end{tabular}




\begin{tabular}{|l|l|}
\hline $\begin{array}{l}\text { 12. Other concomitant or previous malignancy, except: i/ adequately treated in-situ } \\
\text { carcinoma of the uterine cervix, ii/ basal or squamous cell carcinoma of the skin, iii/ } \\
\text { cancer in complete remission for }>5 \text { years, } \\
\text { 13. Patients with known allergy to any excipient of study drugs, } \\
\text { 14. Concomitant administration of prophylactic phenytoin and live attenuated virus } \\
\text { vaccine such as yellow fever vaccine. }\end{array}$ \\
\hline
\end{tabular}

23 
26 Table A12. Evaluation of prognostic value of NLR evolution between baseline and Day 15, and between baseline and Day 30.

27

\begin{tabular}{llllll} 
& & $\mathrm{n}($ events) & $\mathrm{HR}$ & $95 \% \mathrm{CI}$ & pvalue \\
\hline OS & D15 $\leq \mathrm{D} 0$ & $106(77)$ & 1 & & 0.3724 \\
& $\mathrm{D} 15>\mathrm{D} 0$ & $65(48)$ & 0.85 & $0.59-1.22$ & \\
\hline PFS & D15 $\leq$ D0 & $106(90)$ & 1 & & 0.9603 \\
& D15>J0 & $65(55)$ & 1.01 & $0.72-1.41$ &
\end{tabular}

\begin{tabular}{llllll} 
& & $\mathrm{n}($ events $)$ & HR & $95 \% \mathrm{CI}$ & pvalue \\
\hline OS & D30 $\leq \mathrm{D} 0$ & $97(66)$ & 1 & & 0.6875 \\
& $\mathrm{D} 30>\mathrm{D} 0$ & $60(46)$ & 1.08 & $0.74-1.58$ & \\
\hline PFS & D30 $\leq \mathrm{D} 0$ & $97(82)$ & 1 & & 0.9127 \\
& D30 $>$ D0 & $60(50)$ & 0.98 & $0.69-1.40$ & \\
\hline
\end{tabular}

28 
31 Figure A1. Overall survival in the both study cohorts

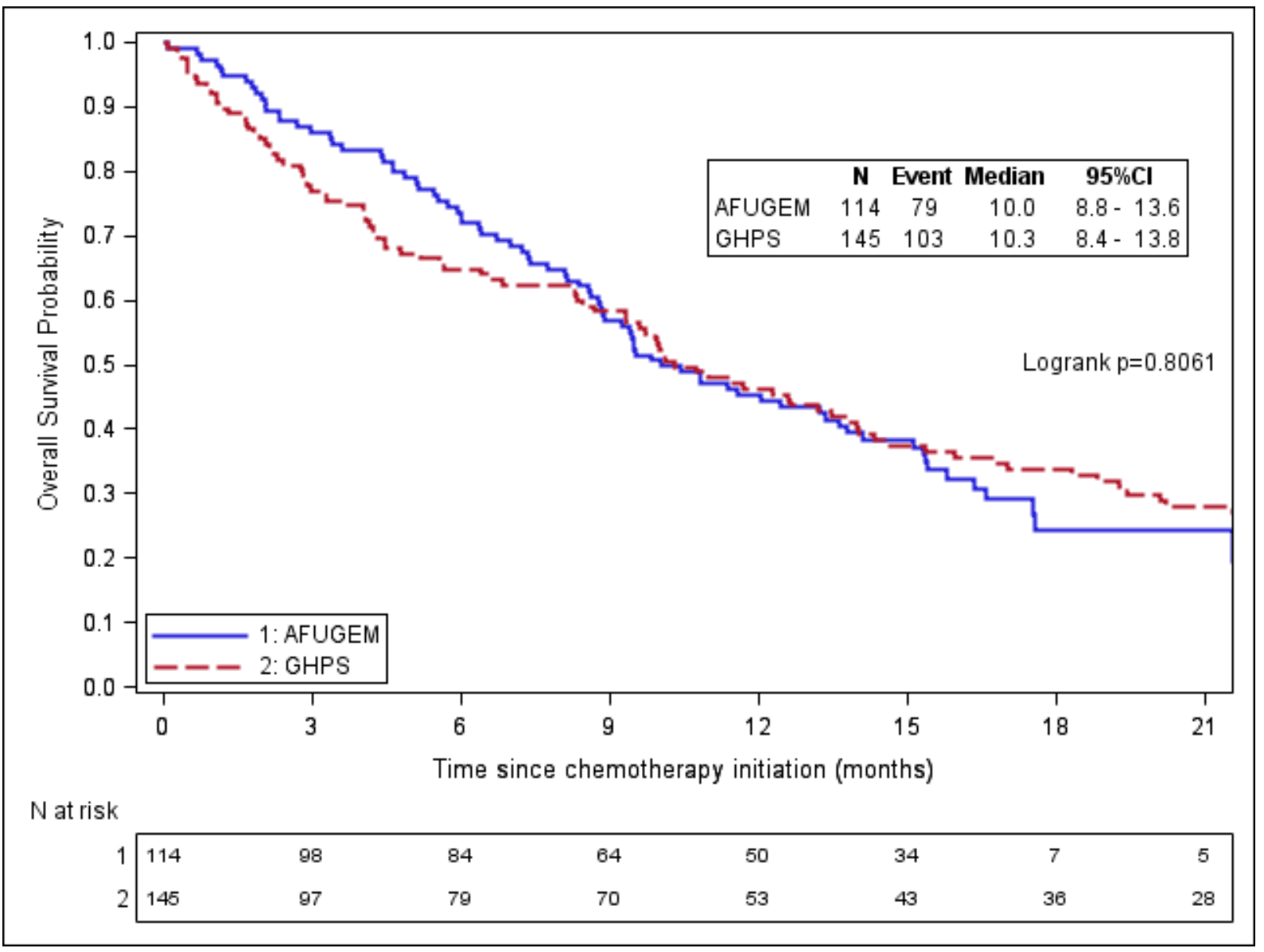


Figure A2. Progression-free survival in the both study cohorts

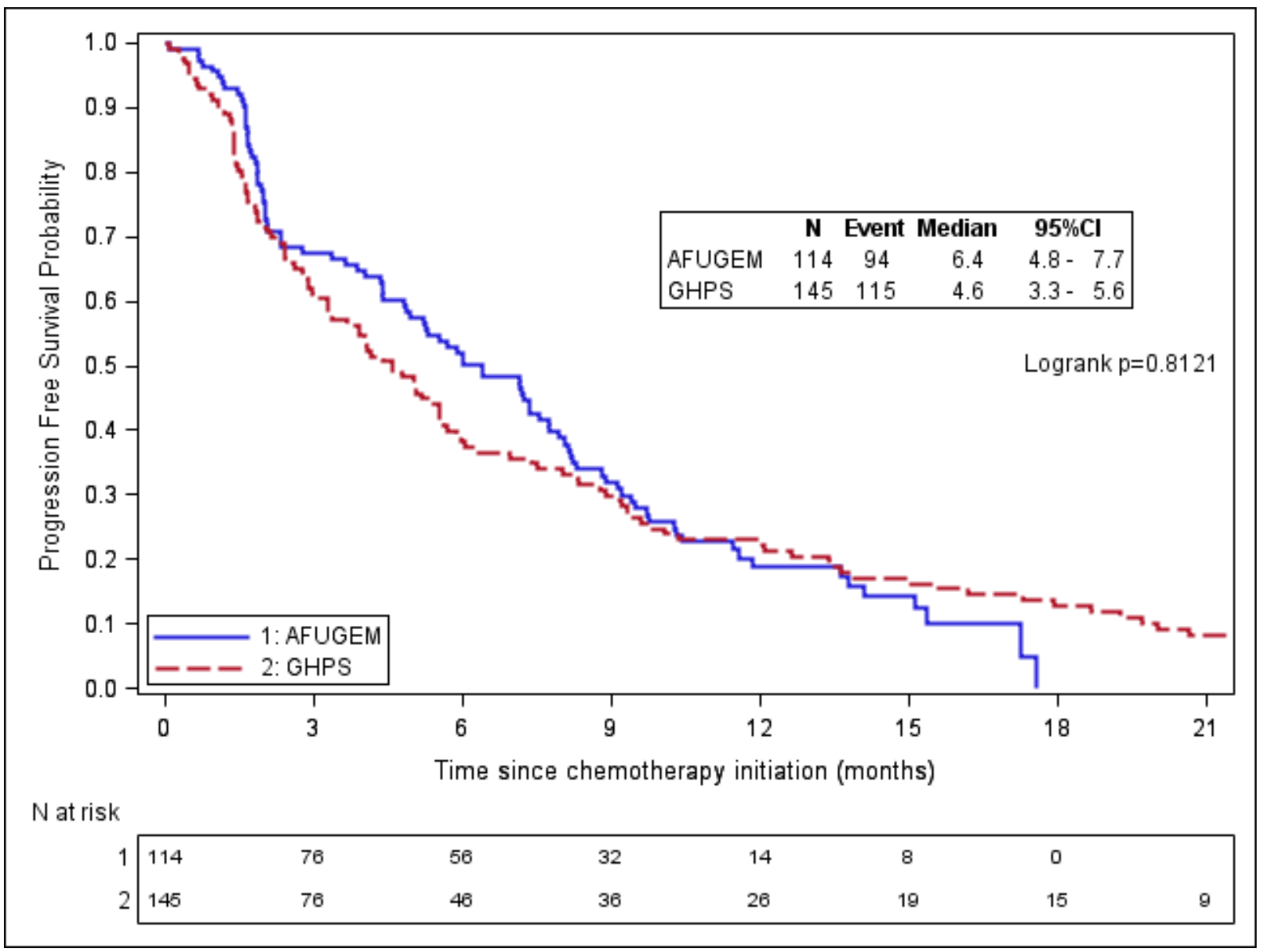

38

39

40

41 
43 Figure A3. Overall survival according to availability of NLR at baseline

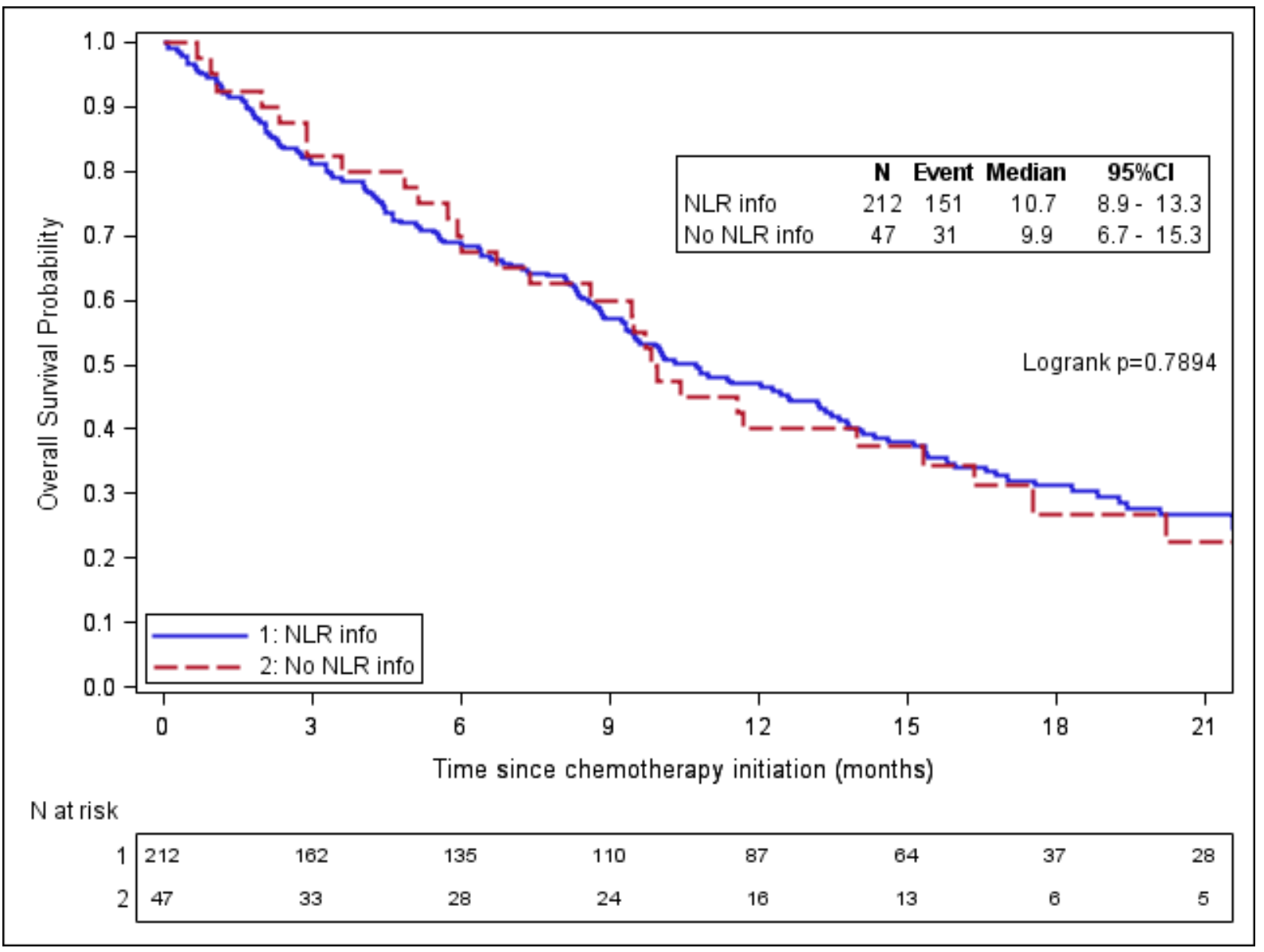

45 
47 Figure A4. Progression-free survival according to availability of NLR at baseline

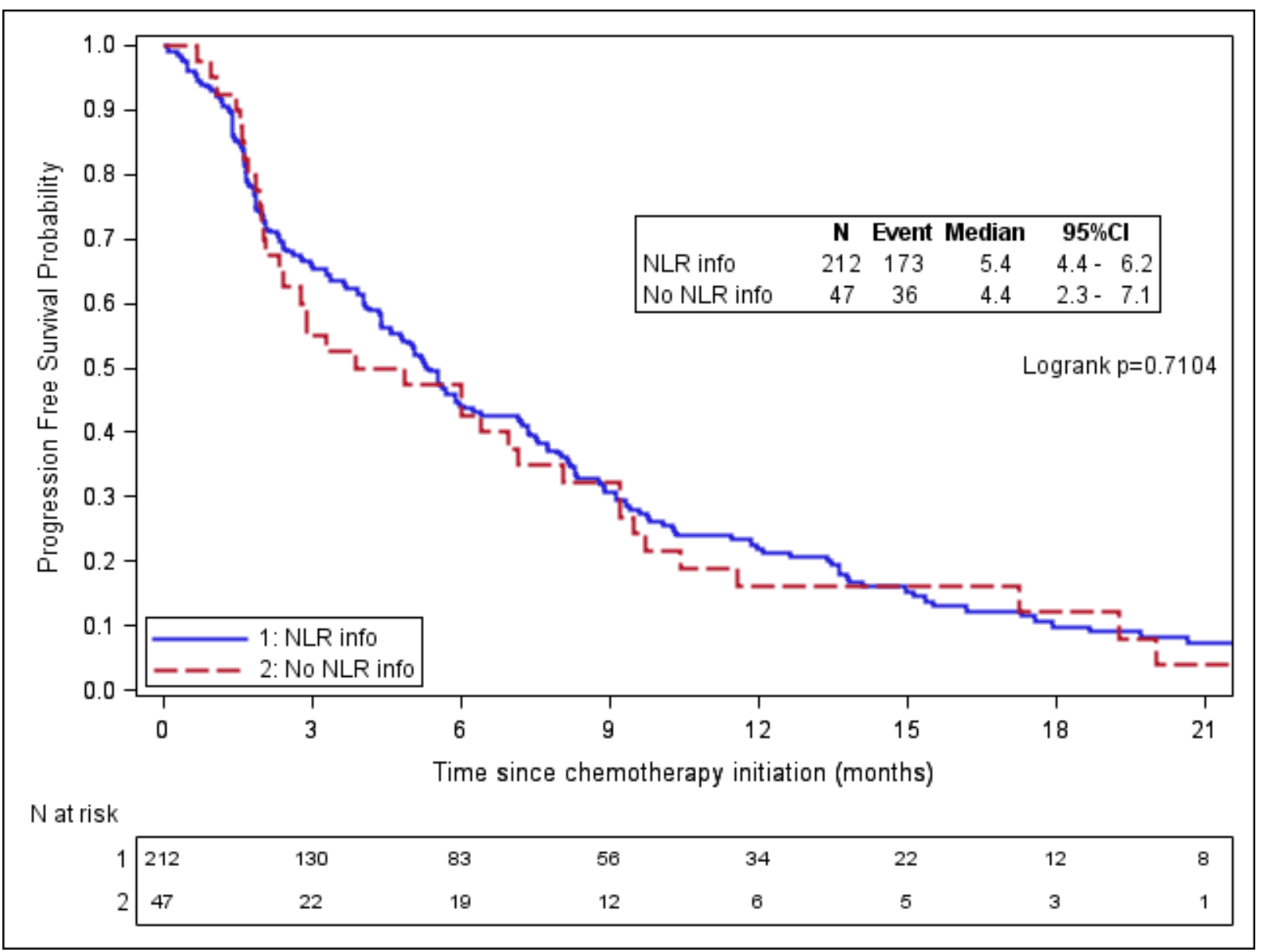


49 Figure A5. Relation between overall survival and NLR using a restricted cubic spline method

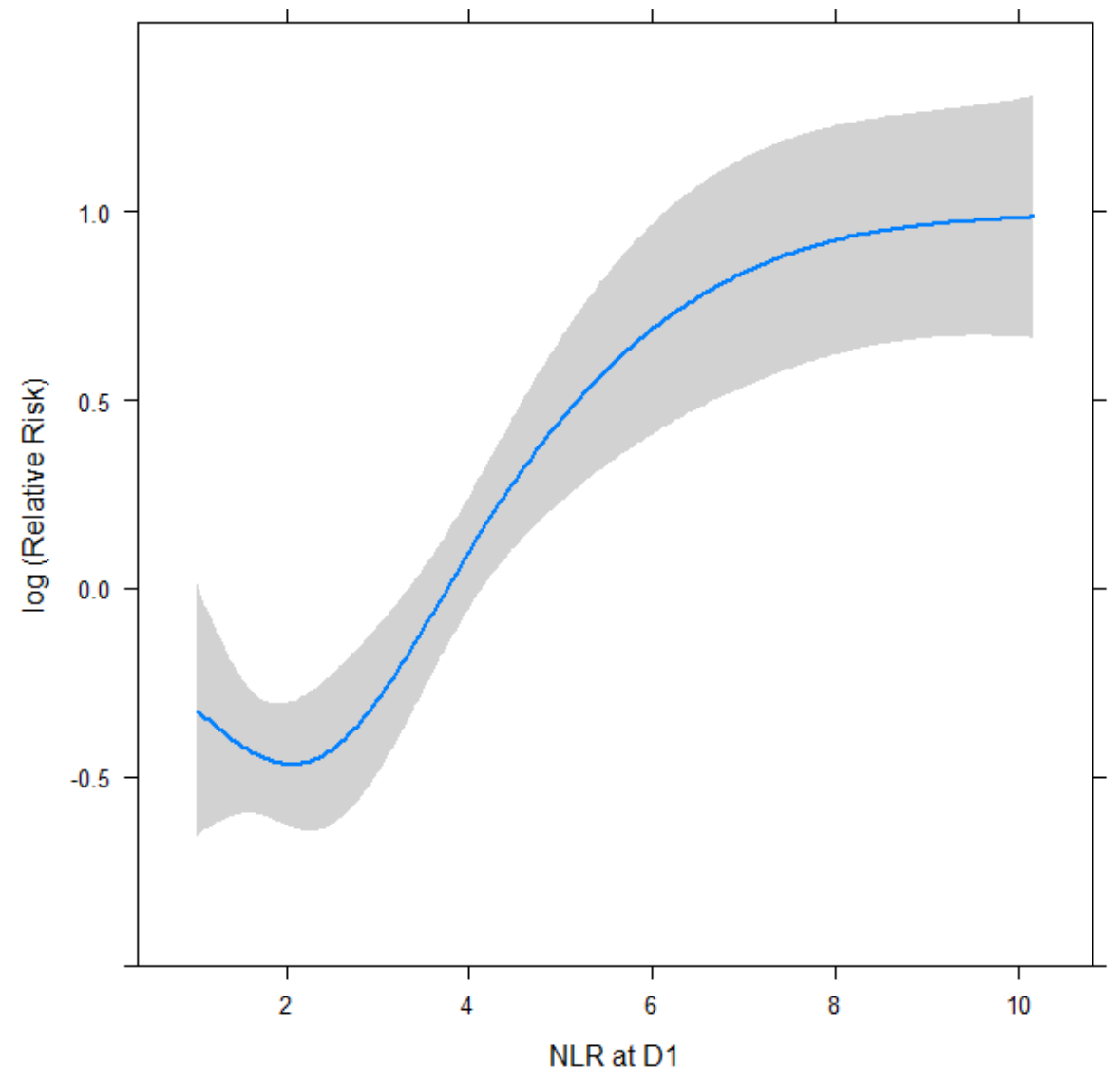

50

51

52

53 
55 Figure A6. Overall survival according to a NLR baseline cut-off of 5

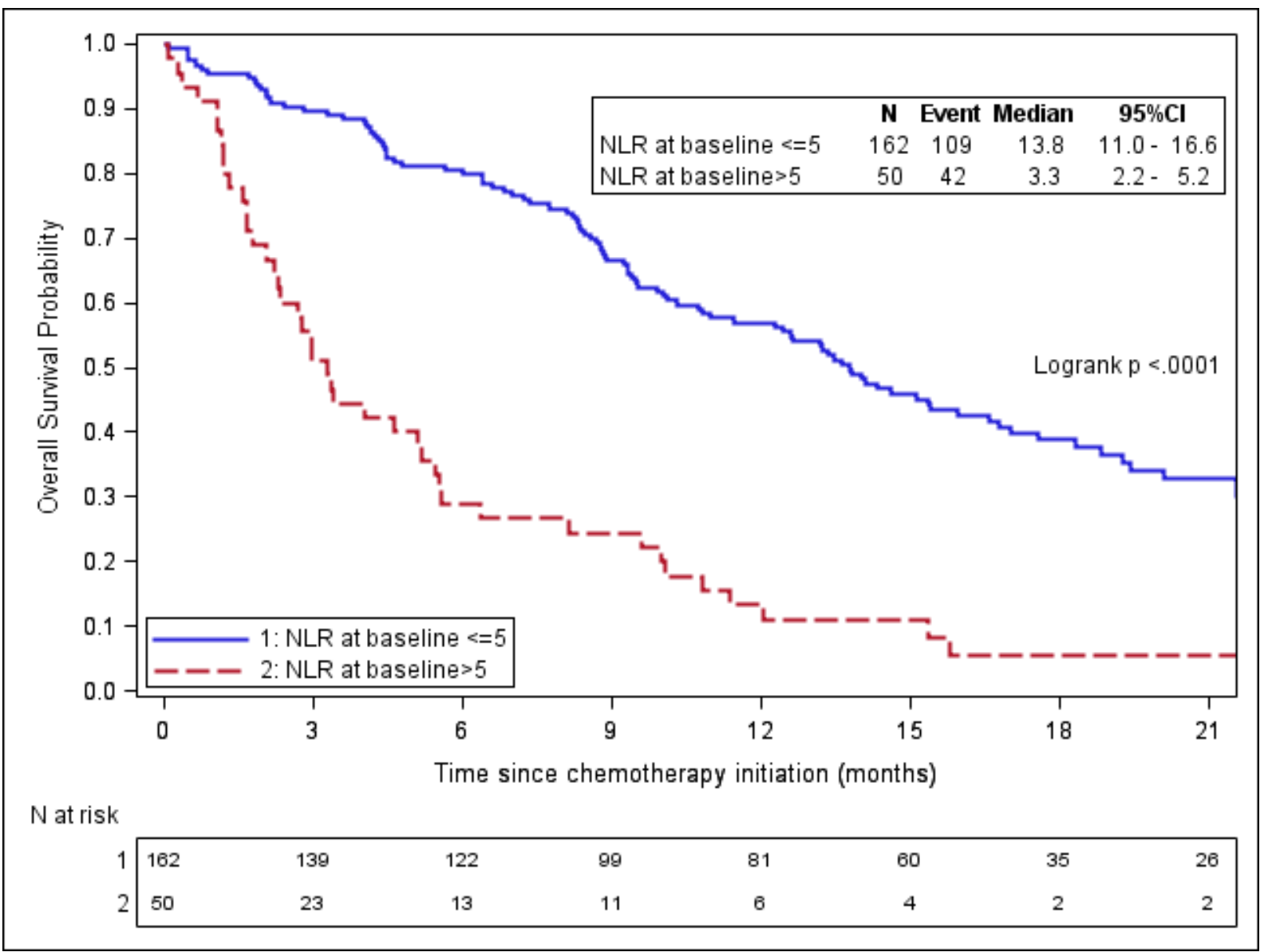

56
57

Reference: NLR $\leq 5=$ HR 3.22 (95\% CI: 2.23-4.64); $P$-value $<0.0001$ 
59 Figure A7. Progression-free survival according to a NLR baseline cut-off of 5

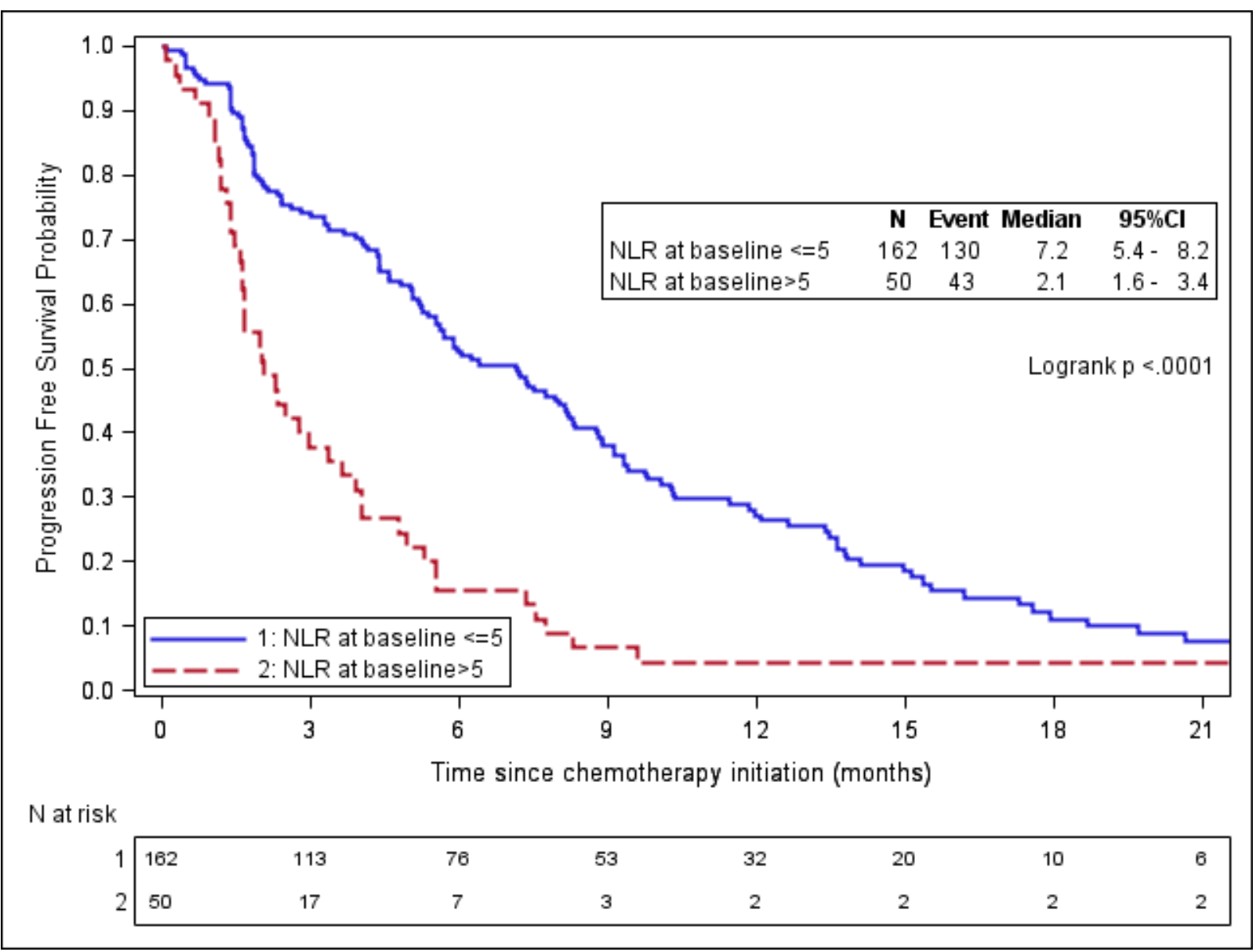

61 Reference: NLR $\leq 5=\mathrm{HR} 2.37$ (95\% CI: 1.67-3.39); $P$-value $<0.0001$

62

63

64 
65

66

67

68

69

70

71

72

73

74

75

76

77

78

79

80

81 
83 Figure A.8. Overall survival according to a NLR baseline cut-off of 5 (after exclusion of the 10 patients with ECOG PS 3)

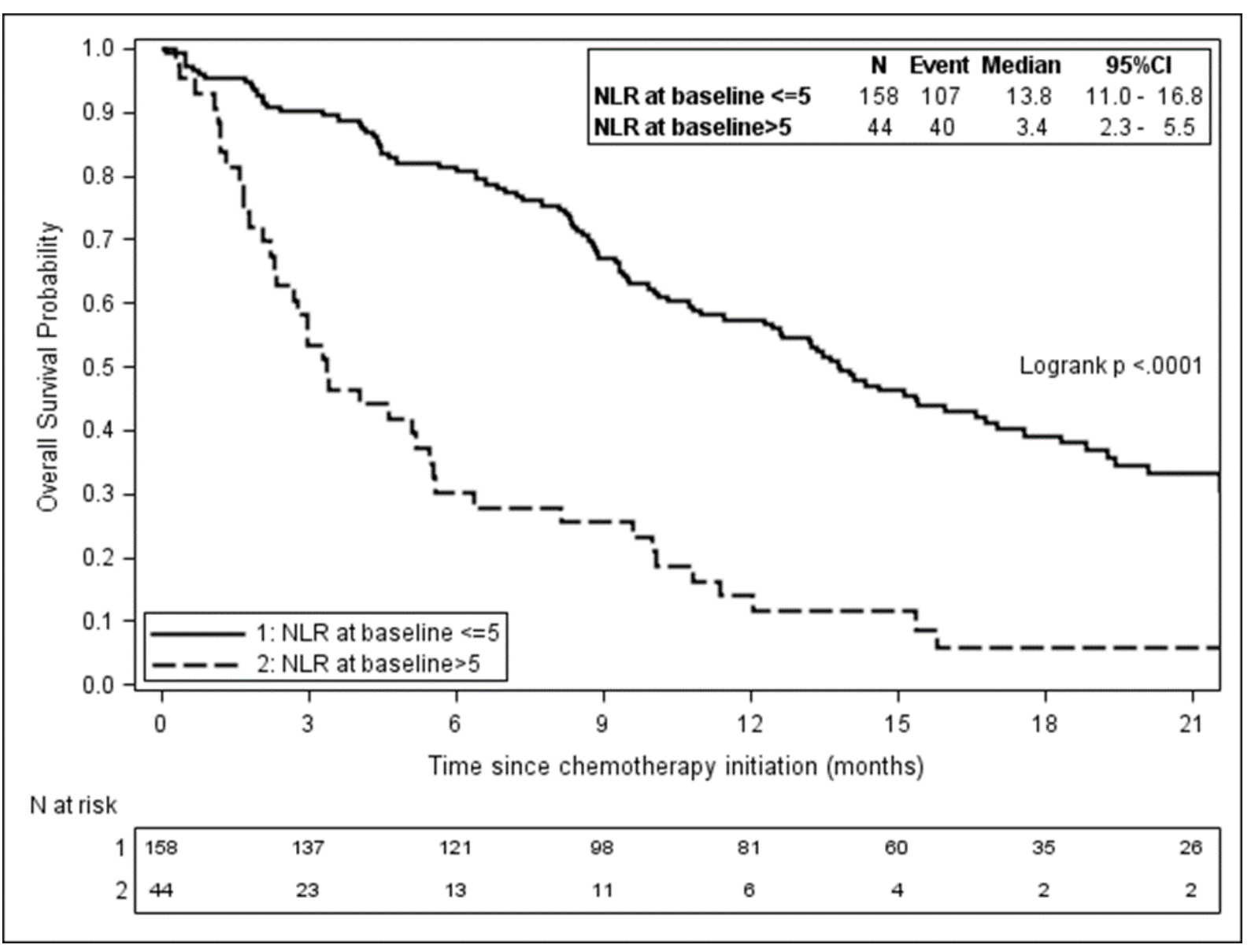

84

$85 \quad \mathrm{HR}=3.15(95 \% \mathrm{CI}: 2.17-4.58) ; \mathrm{p}<0.0001$ 
91 Figure A.9. Progression-free survival according to a NLR baseline cut-off of 5 (after exclusion of the 10 patients with ECOG PS 3)

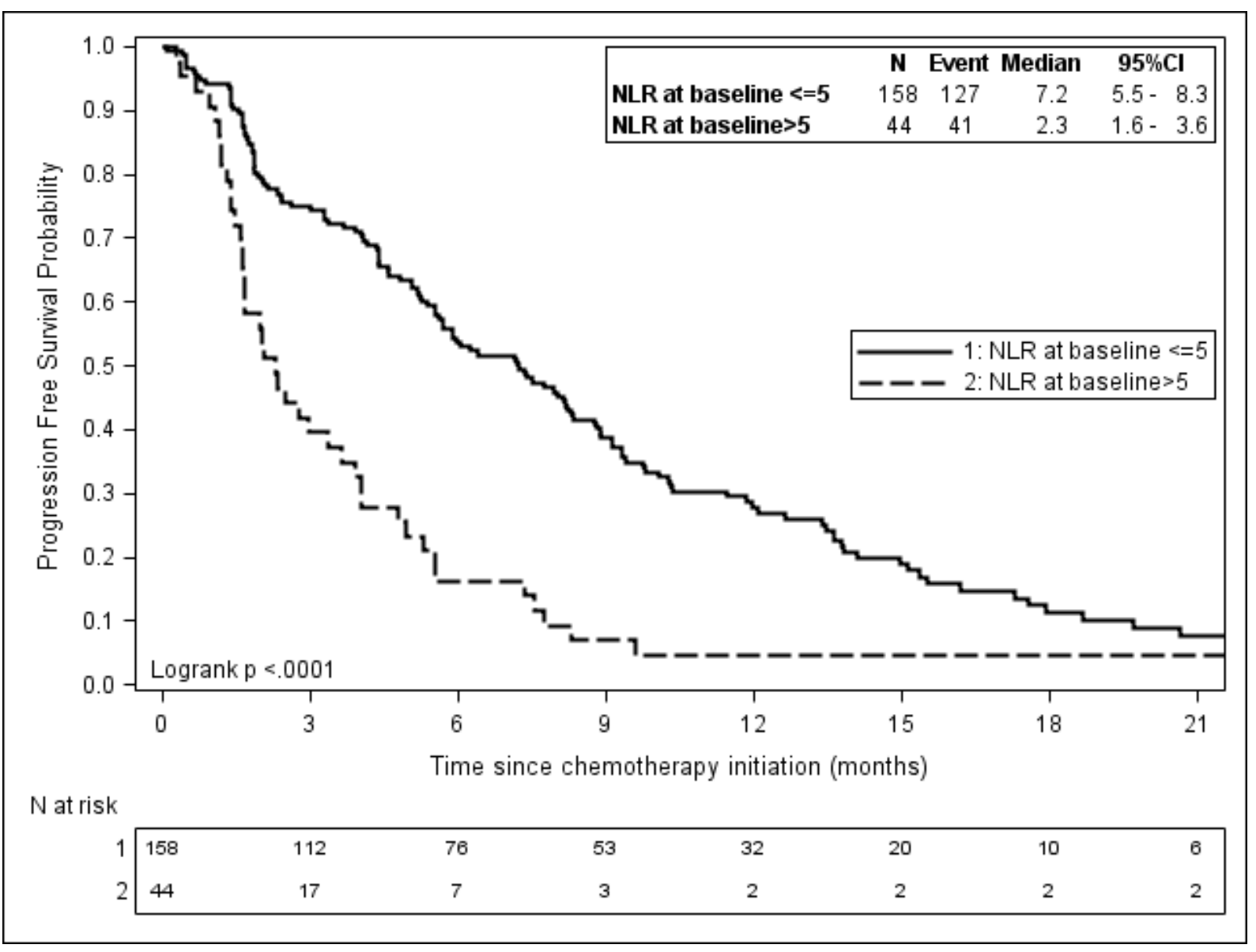

$93 \quad \mathrm{HR}=2.33(95 \% \mathrm{CI}: 1.62-3.34) ; \mathrm{p}<0.0001$ 
100 Figure A10. Progression-free survival according to NLR at baseline and NLR on day 15 of cycle

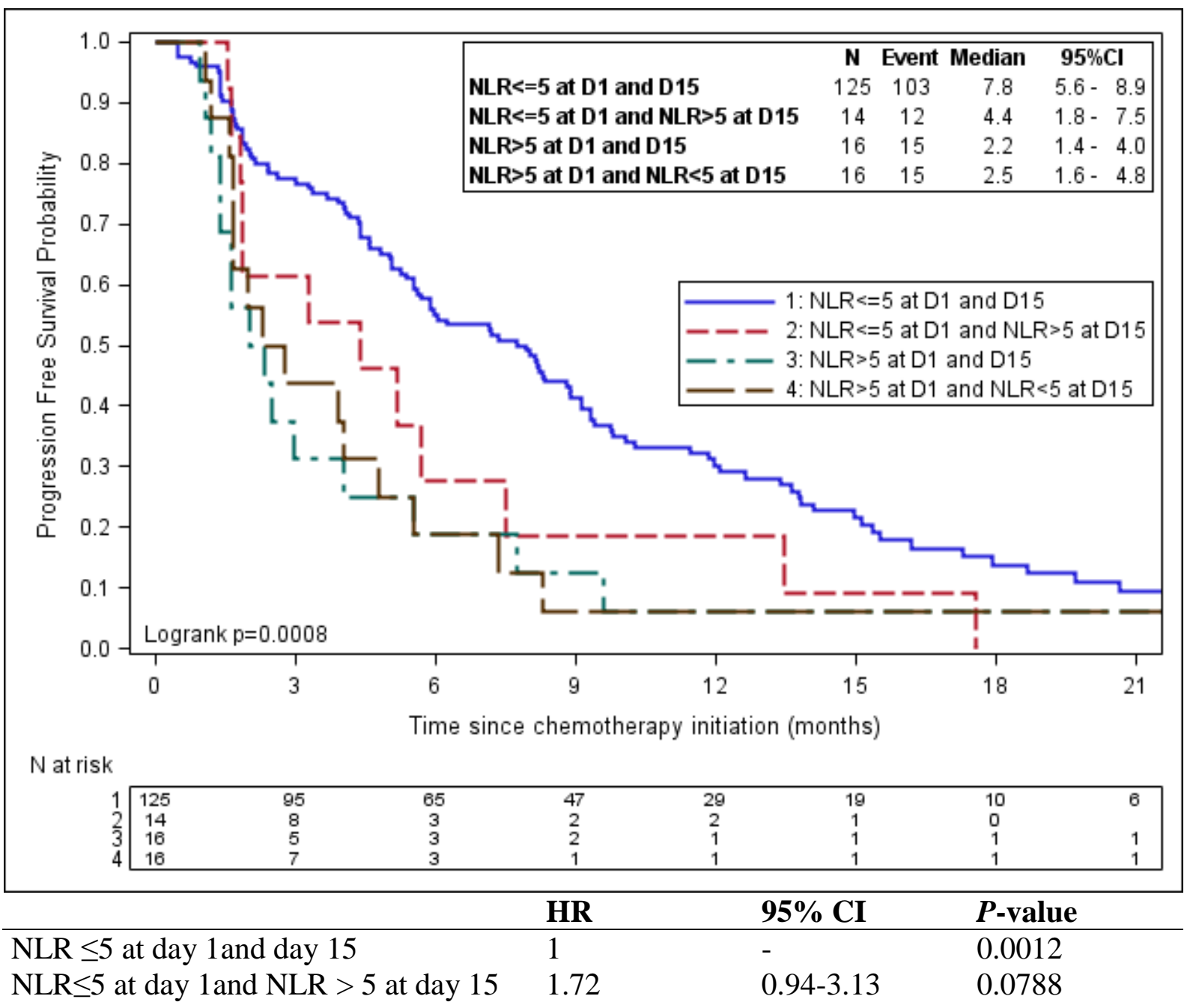


NLR $>5$ at day 1 and day 15

$\mathrm{NLR}>5$ at day 1 and NLR $\leq 5$ at day 15

$1.35-4.04$

0.0023
$1.23-3.68$
2.12
0.0071

103 With a Cox time-varying covariate model and NLR transformed with log, HR=1.68 (95\% CI 1.37-2.06); $P<0.0001$.

104 With a Cox time-varying covariate model and NLR $>5$ as factor, HR=2.26 (95\% CI 1.57-3.25); $P<0.0001$. 
107 Figure A11. Overall survival according to NLR at baseline and NLR on day 15 of cycle (after exclusion of the 10 patients with ECOG PS 3 )

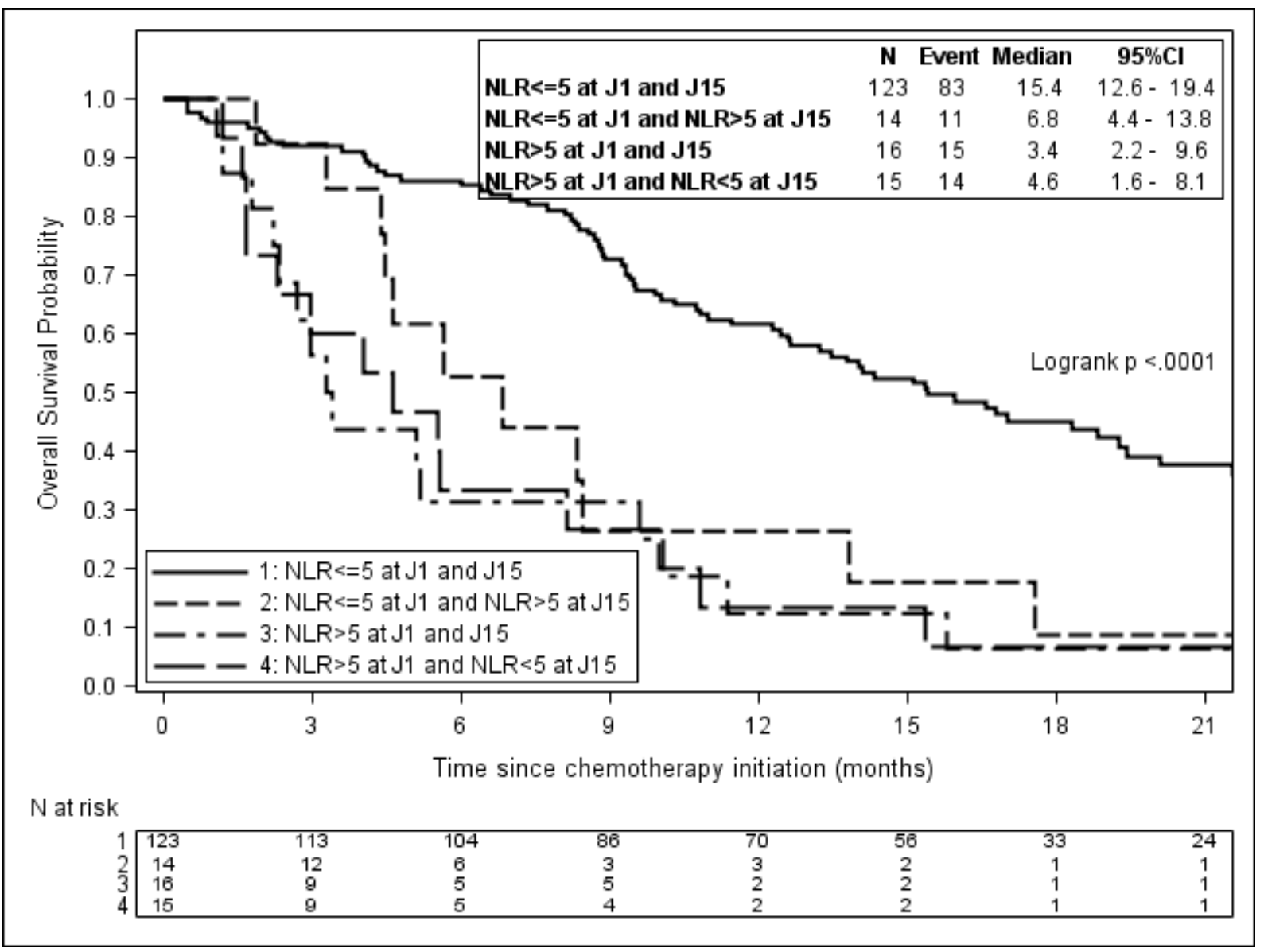


112 Figure A12. Progression-free survival according to NLR at baseline and NLR on day 15 of cycle (after exclusion of the 10 patients with ECOG PS 3 )

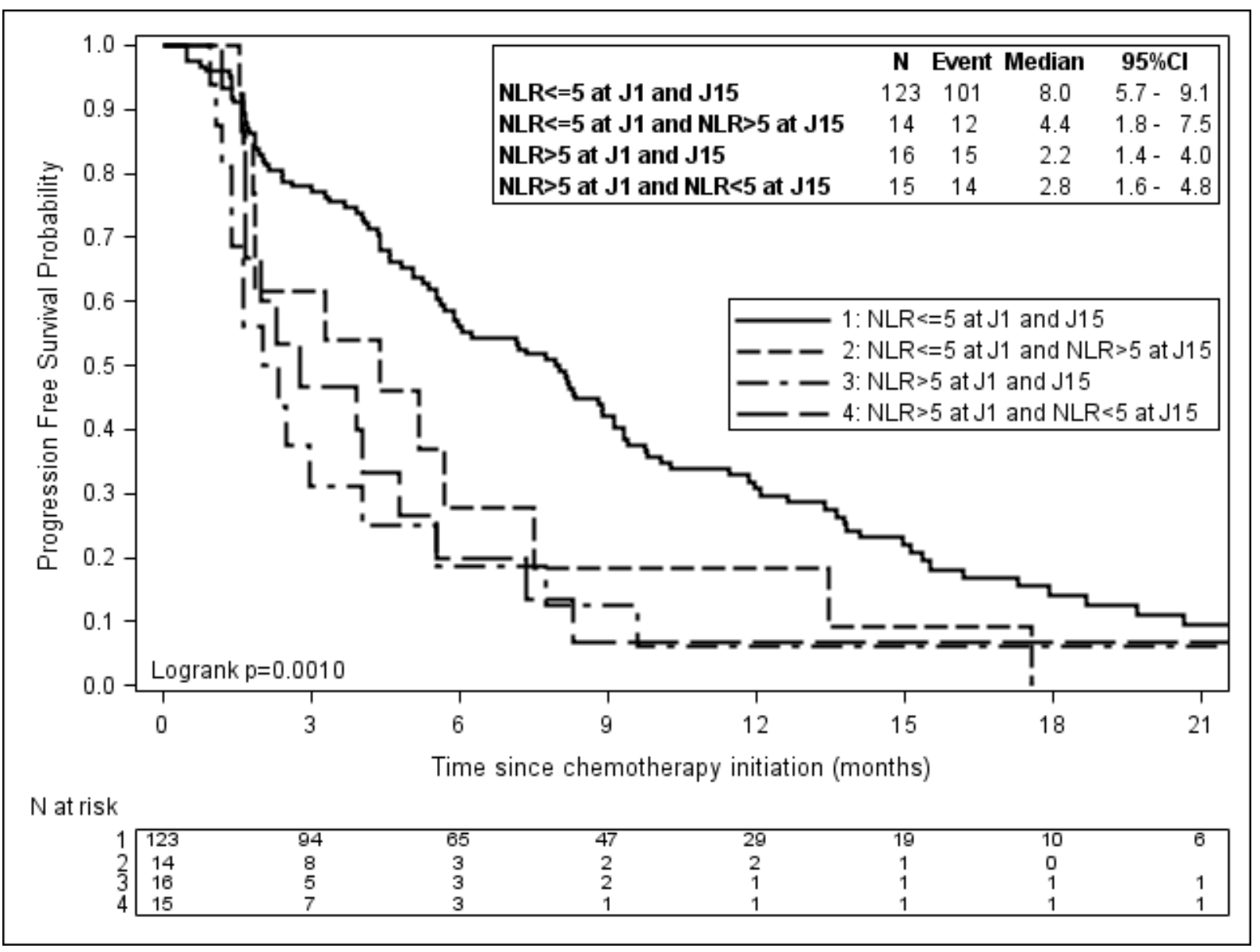


118 Figure A13. Overall survival according to NLR at baseline in A) the AFUGEM cohort and B) in the GHPS cohort A

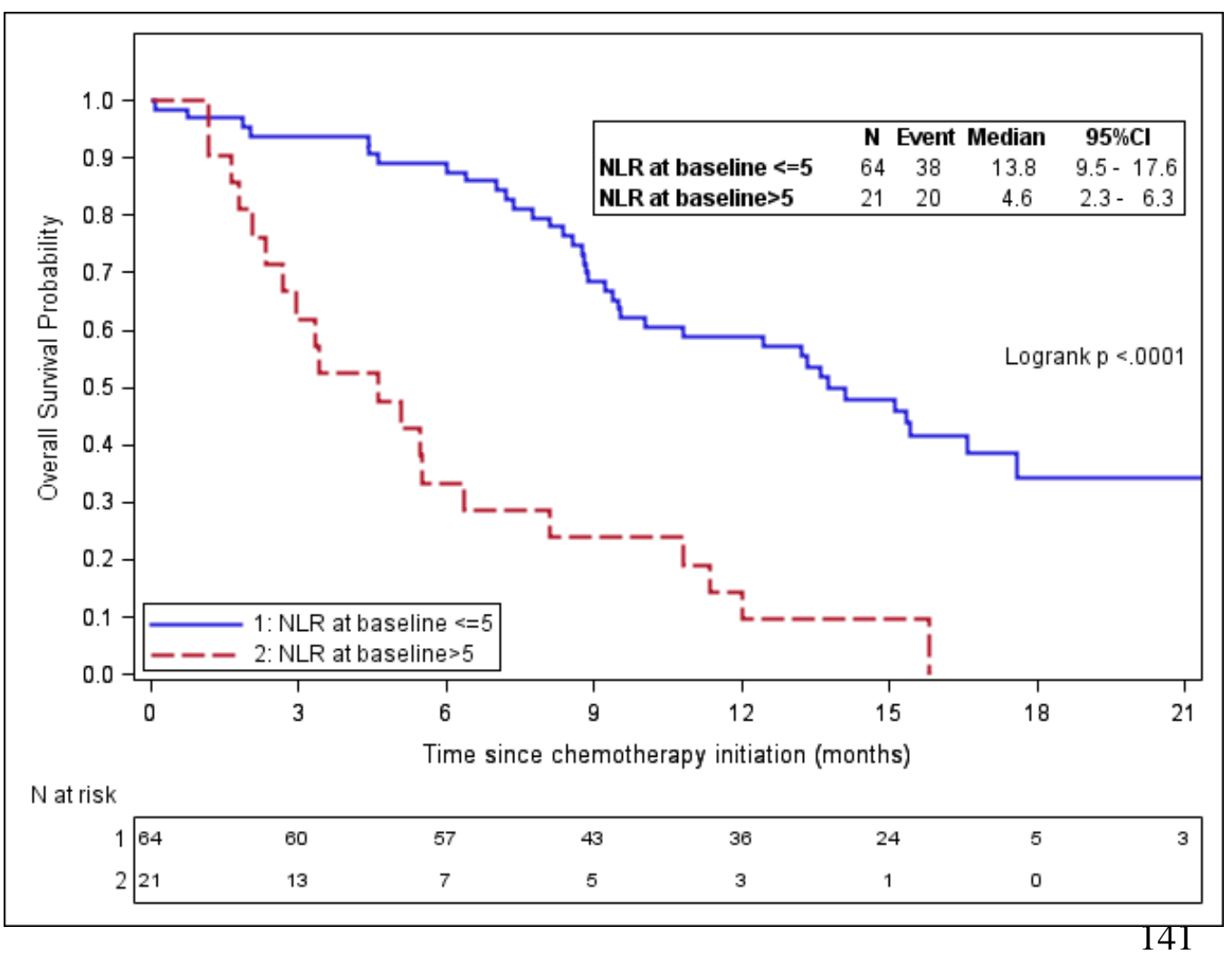

142

143 B

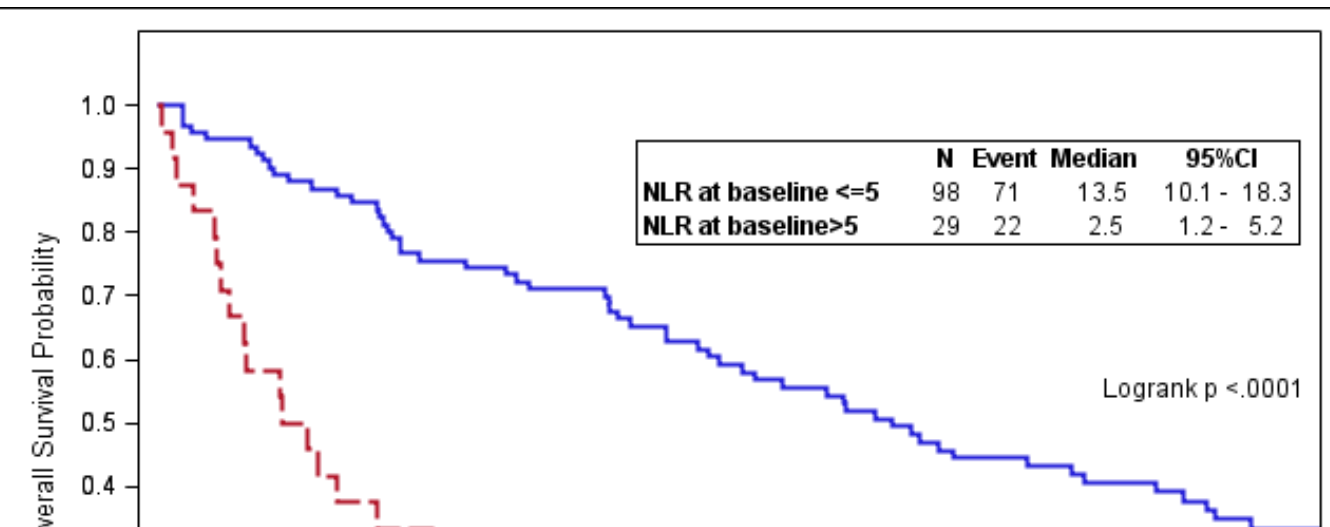




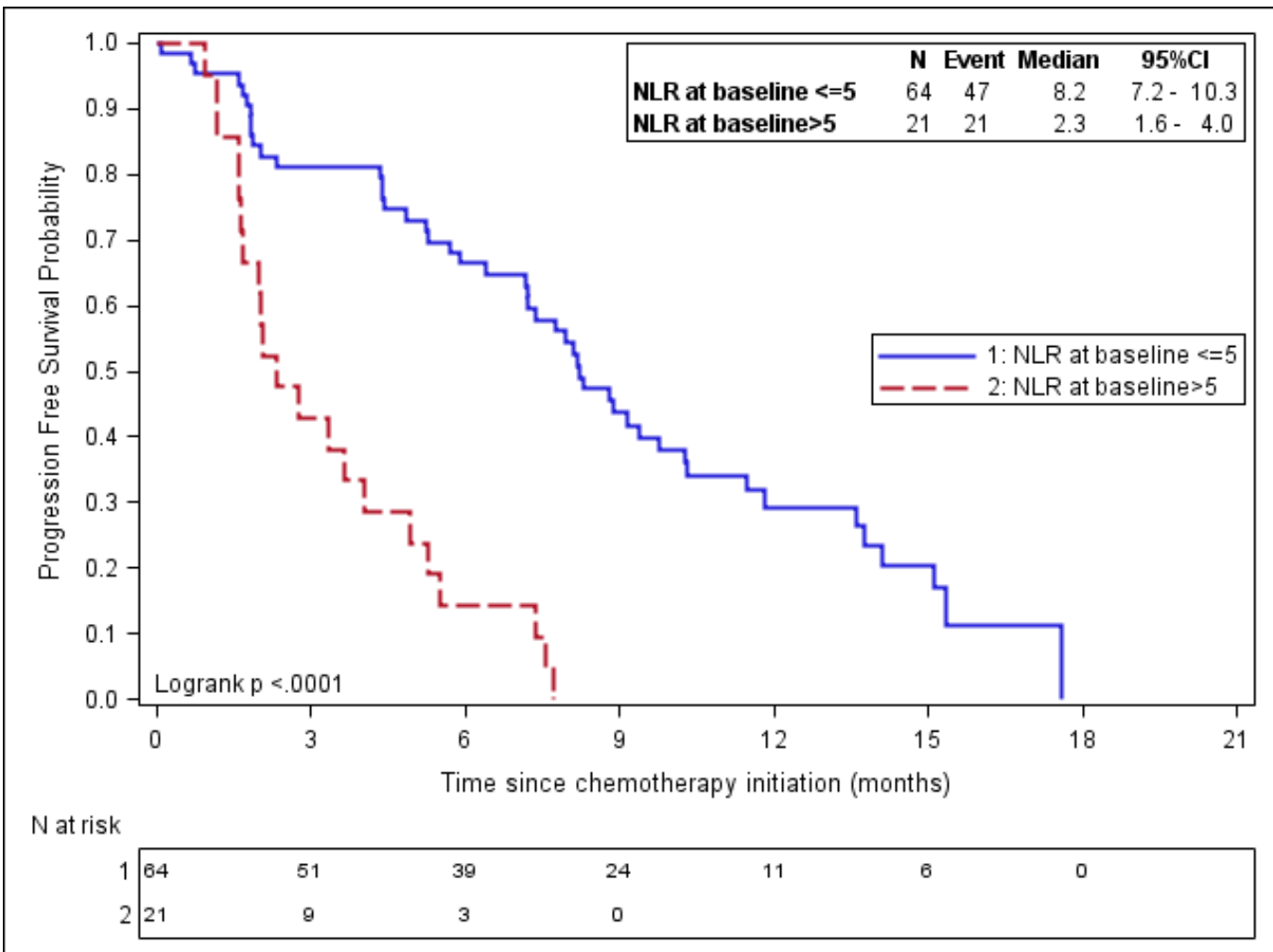

Figure A14. Progression-free survival according to NLR at baseline in A) the AFUGEM cohort and B) in the GHPS cohort 


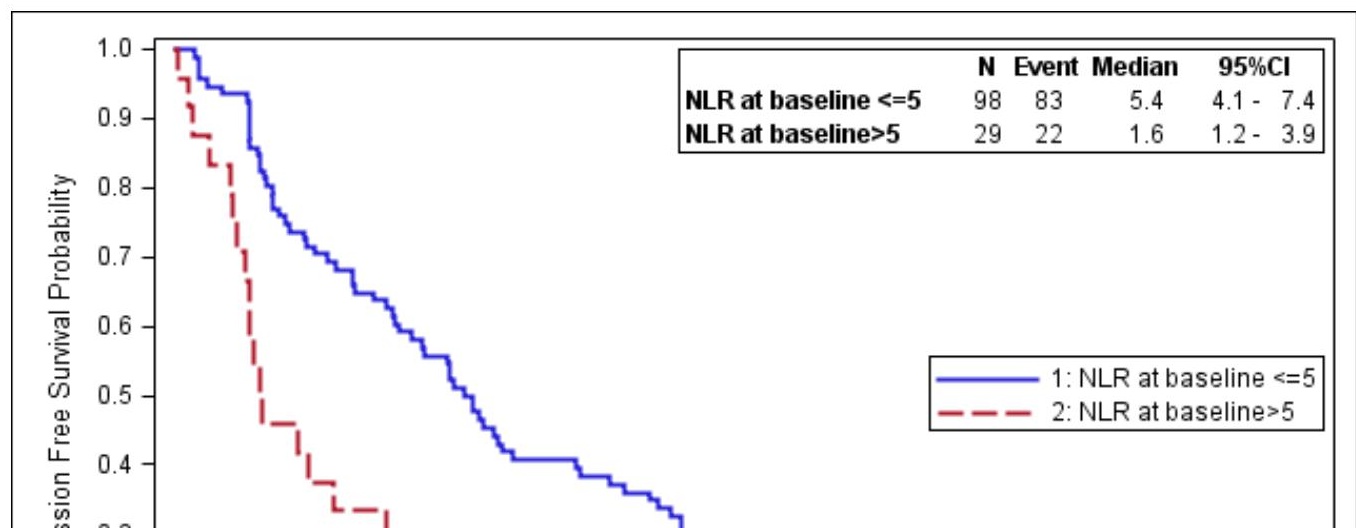


217 Figure A15. Overall survival according to NLR on day 1 and day 15 of cycle in

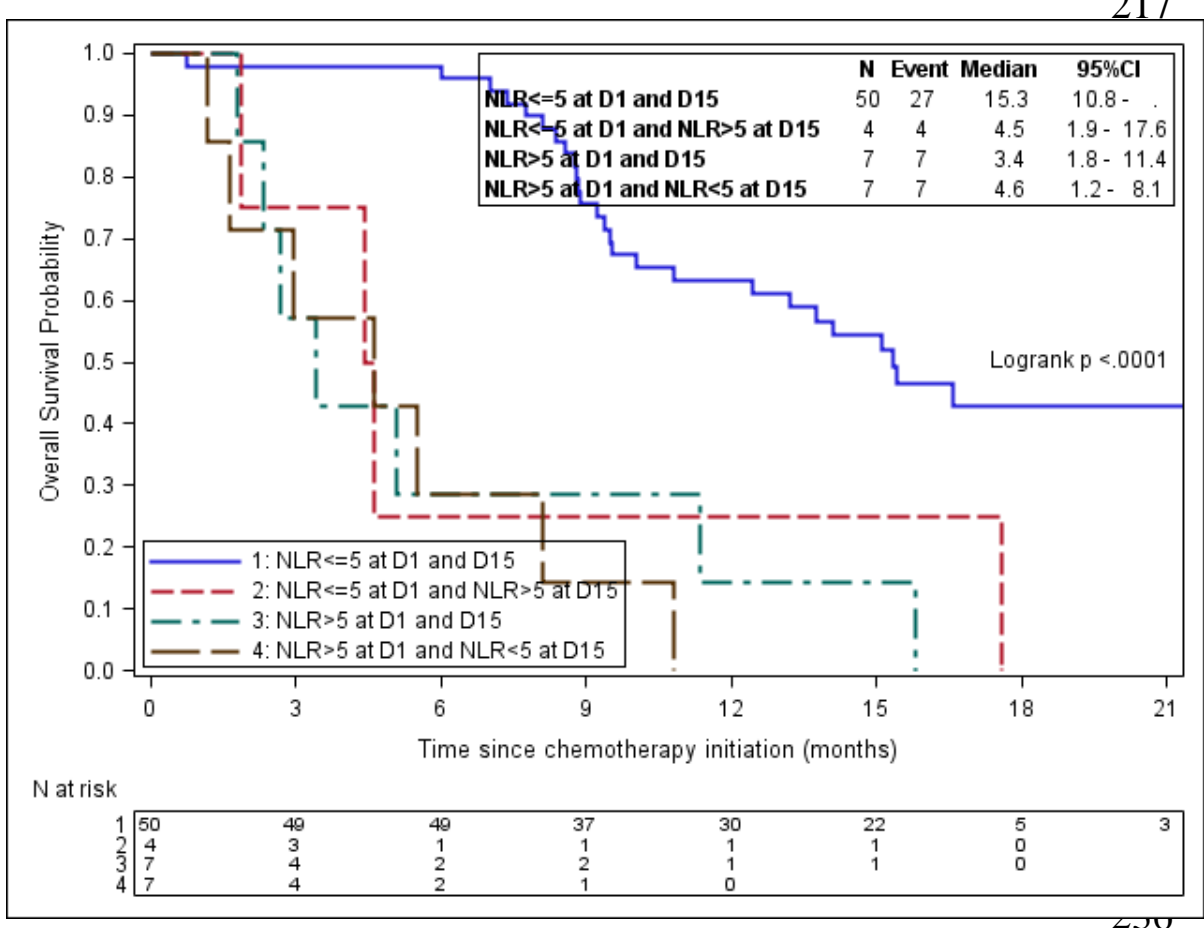

A) the AFUGEM cohort and B) in the GHPS cohort

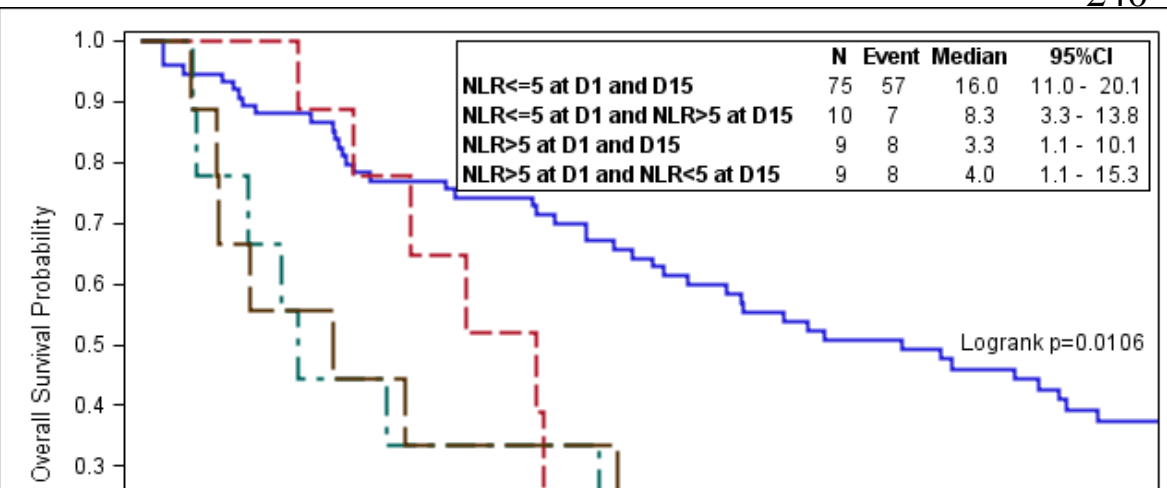




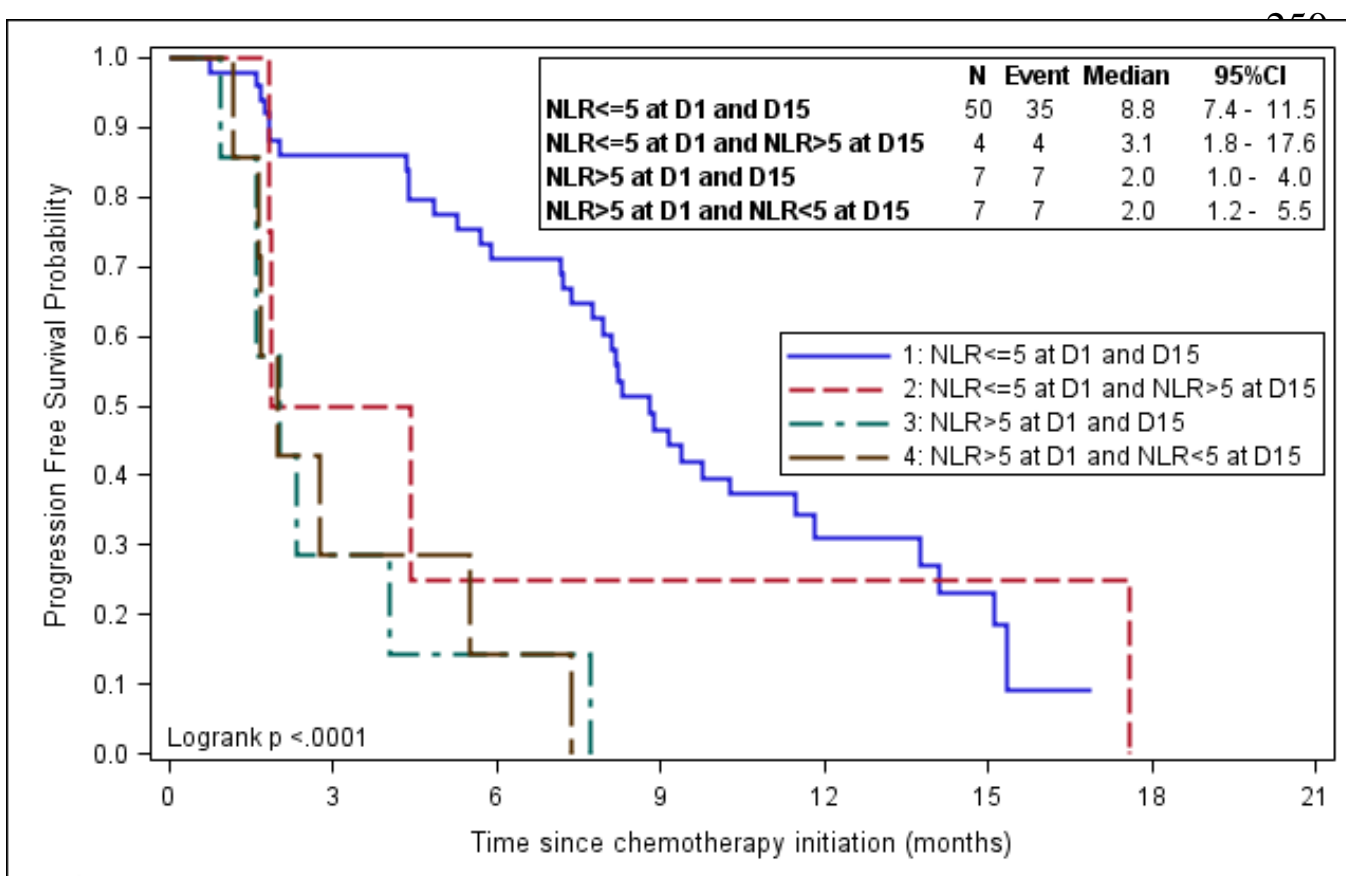

$\mathrm{N}$ at ris

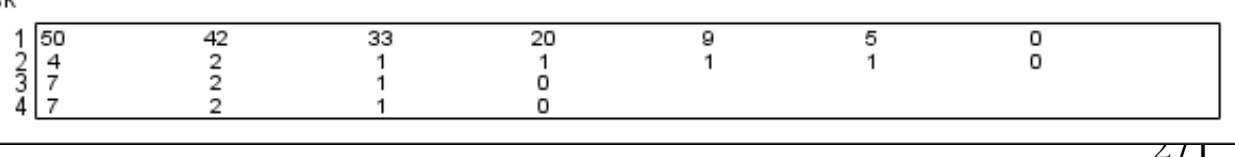

Figure A16. Progression-free survival according to NLR on day 1 and day 15 of cycle in A) the AFUGEM cohort and B) the GHPS cohort 
Figure A17. Evolution of NLR over time in A) the AFUGEM cohort and B) the GHPS cohort

319 A

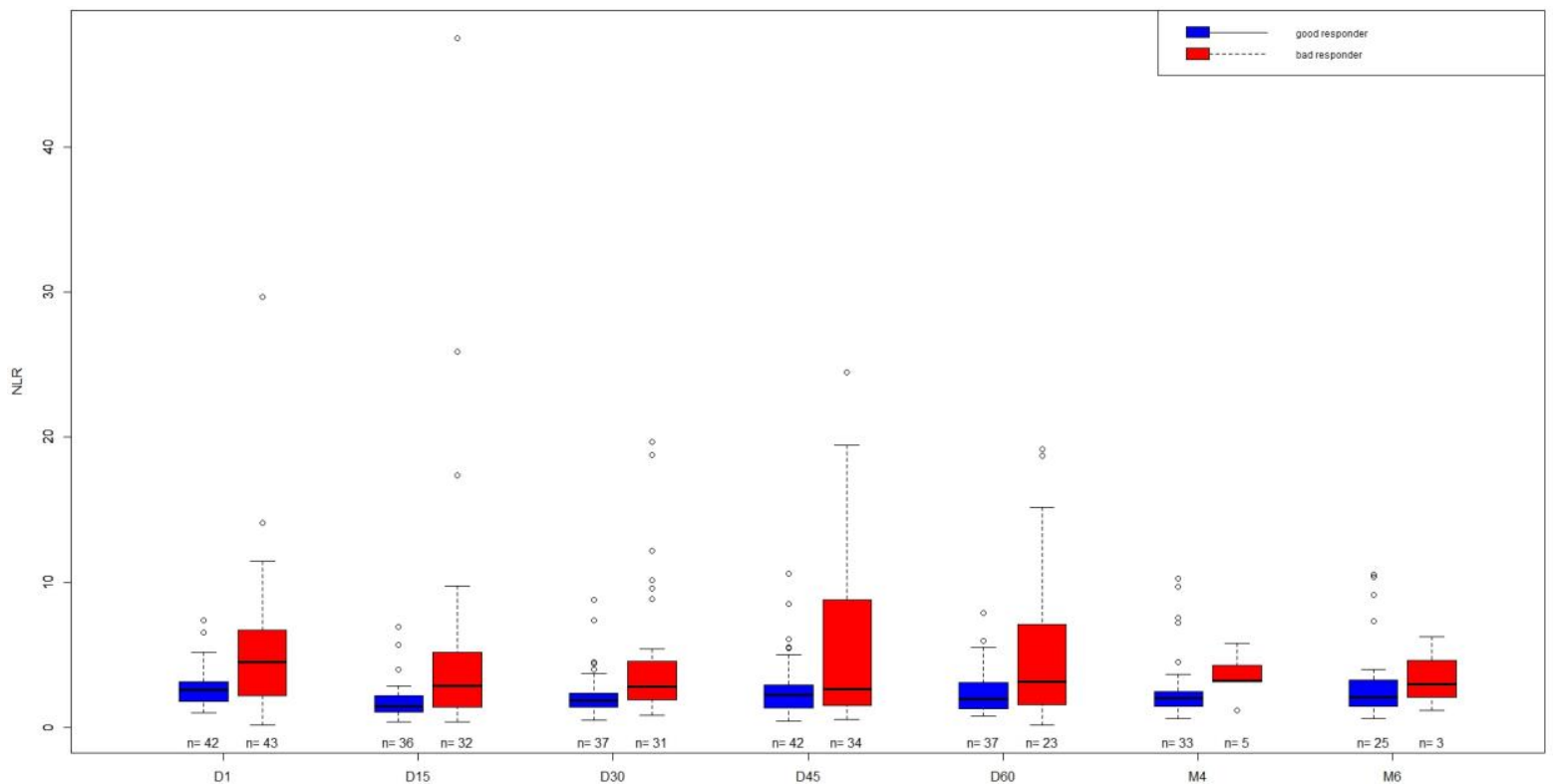




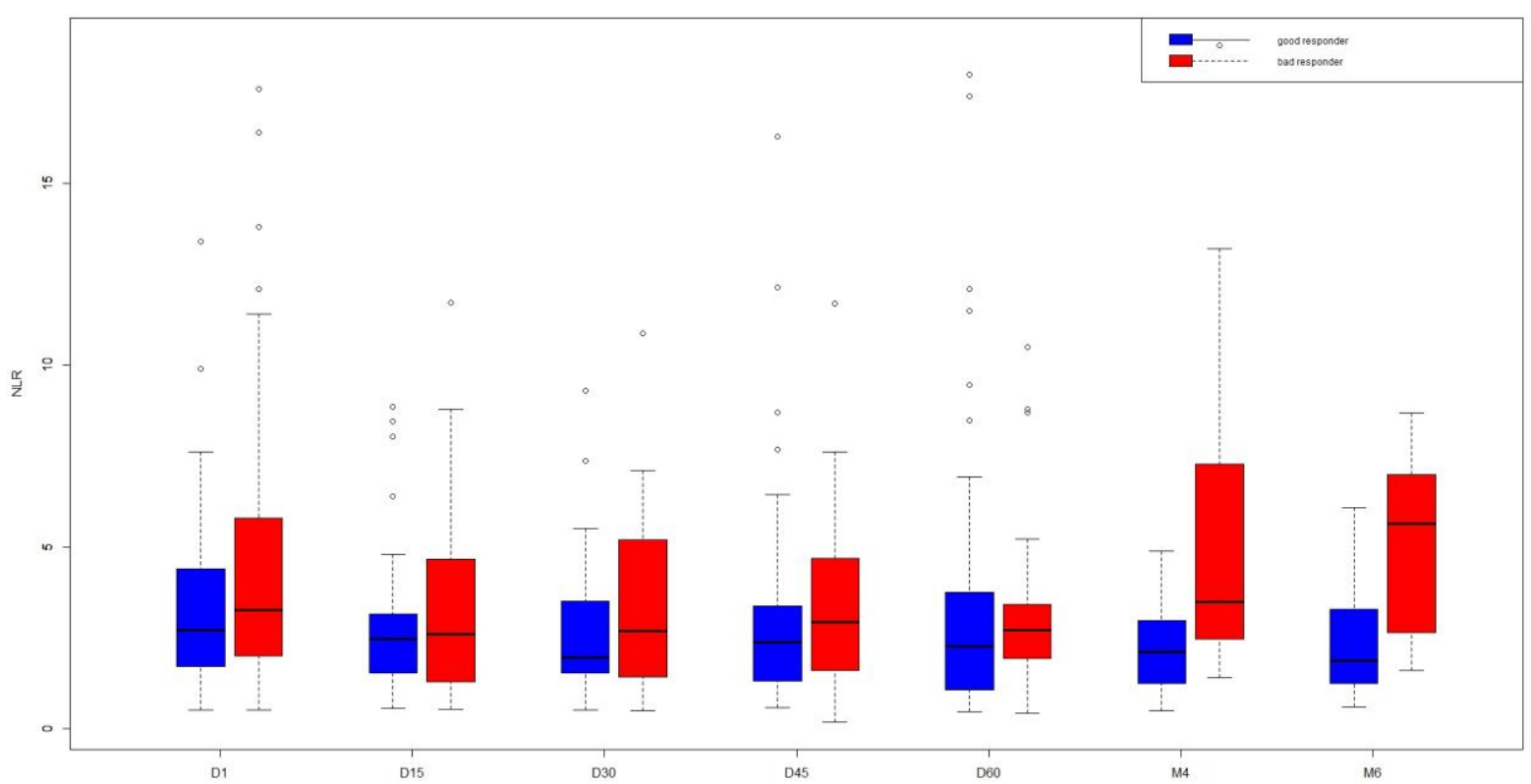

322

323

324

325

329

330

331 Figure A18. Overall survival in patients with baseline NLR $<5$ according to the presence of ctDNA in the GHPS cohort 


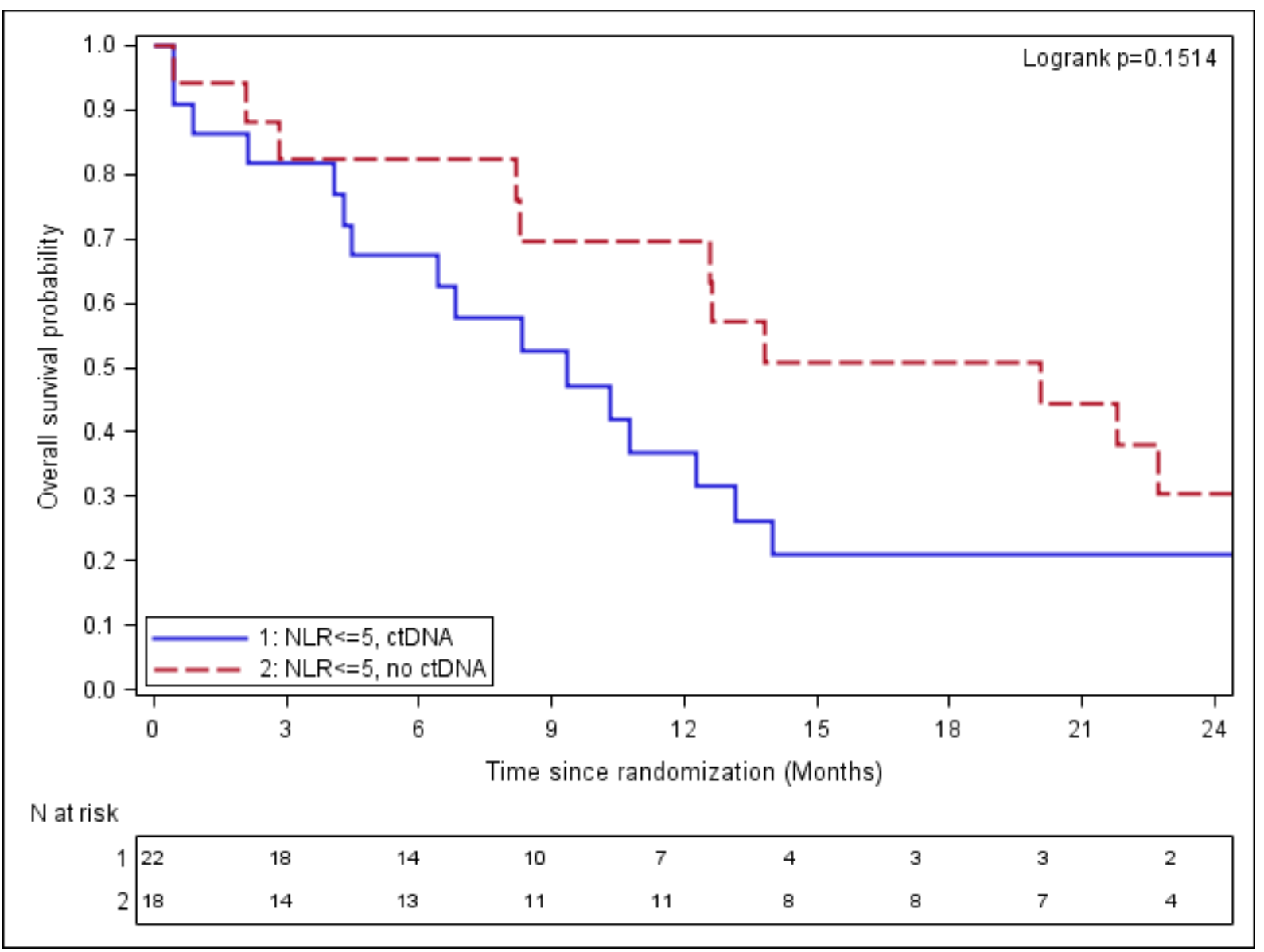


Figure A19. Progression-free survival in patients with baseline NLR $<5$ according to the presence of ctDNA in the GHPS cohort

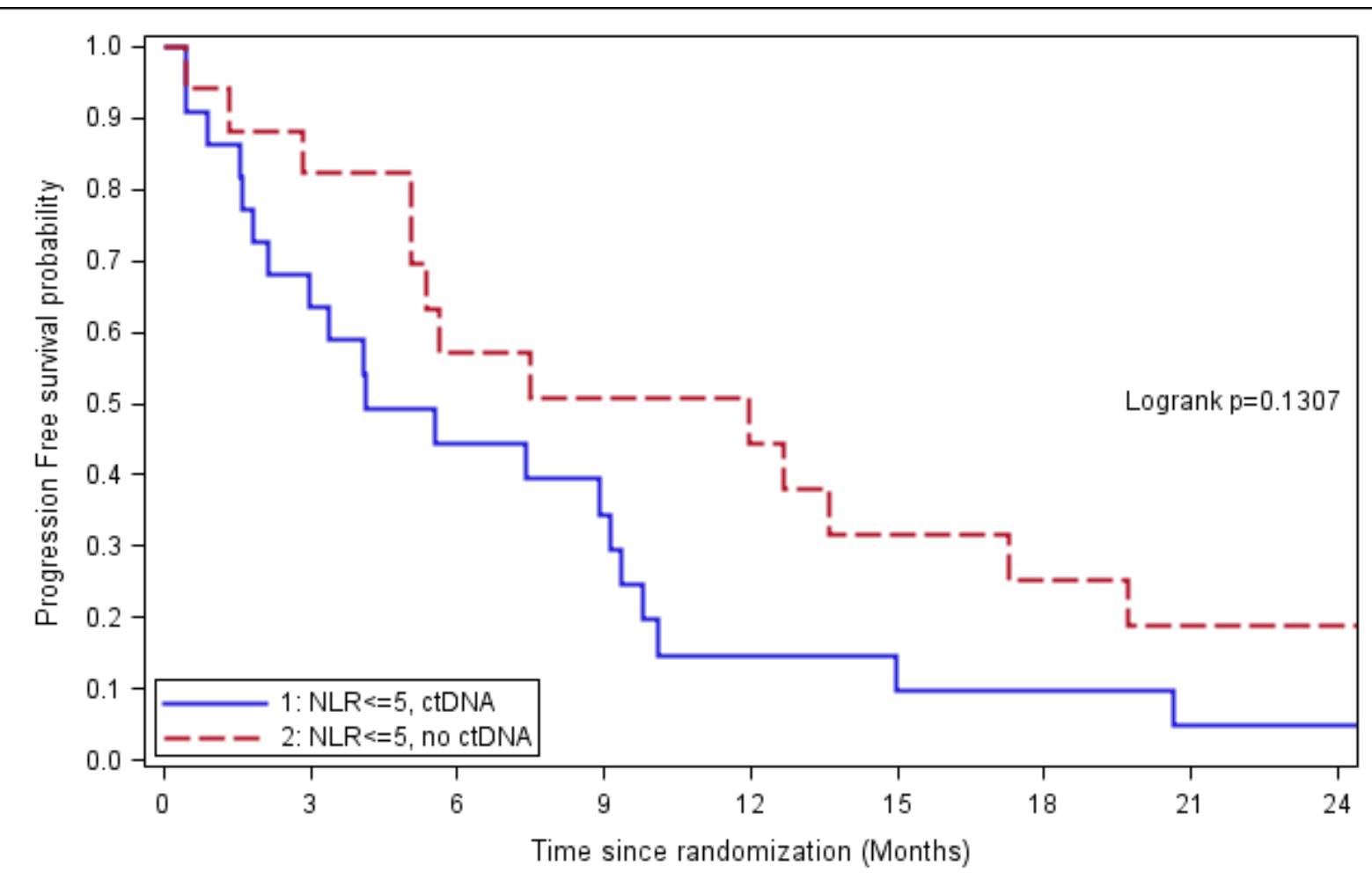

336

\begin{tabular}{|lllllllll|}
\hline 22 & 14 & 9 & 7 & 3 & 2 & 2 & 1 & 1 \\
2 & 14 & 9 & 8 & 7 & 5 & 4 & 3 & 3 \\
\hline
\end{tabular}

